\title{
A physically based framework for modeling the organic fractionation of sea spray aerosol from bubble film Langmuir equilibria
}

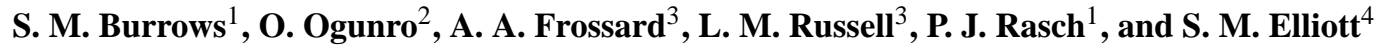 \\ ${ }^{1}$ Atmospheric Science and Global Change Division, Pacific Northwest National Laboratory, Richland, Washington, USA \\ ${ }^{2}$ Ocean and Atmospheric Chemistry, Department of Chemistry, New Mexico Institute of Mining and Technology, \\ Socorro, New Mexico \\ ${ }^{3}$ Scripps Institution of Oceanography, University of California, San Diego, La Jolla, California, USA \\ ${ }^{4}$ Climate Ocean Sea Ice Modeling team, Computational Physics and Methods group, Los Alamos National Laboratory, \\ Los Alamos, New Mexico, USA
}

Correspondence to: S. M. Burrows (susannah.burrows@pnnl.gov)

Received: 13 January 2014 - Published in Atmos. Chem. Phys. Discuss.: 3 March 2014

Revised: 14 October 2014 - Accepted: 29 October 2014 - Published: 19 December 2014

\begin{abstract}
The presence of a large fraction of organic matter in primary sea spray aerosol (SSA) can strongly affect its cloud condensation nuclei activity and interactions with marine clouds. Global climate models require new parameterizations of the SSA composition in order to improve the representation of these processes. Existing proposals for such a parameterization use remotely sensed chlorophyll $a$ concentrations as a proxy for the biogenic contribution to the aerosol. However, both observations and theoretical considerations suggest that existing relationships with chlorophyll $a$, derived from observations at only a few locations, may not be representative for all ocean regions.

We introduce a novel framework for parameterizing the fractionation of marine organic matter into SSA based on a competitive Langmuir adsorption equilibrium at bubble surfaces. Marine organic matter is partitioned into classes with differing molecular weights, surface excesses, and Langmuir adsorption parameters. The classes include a lipid-like mixture associated with labile dissolved organic carbon (DOC), a polysaccharide-like mixture associated primarily with semilabile DOC, a protein-like mixture with concentrations intermediate between lipids and polysaccharides, a processed mixture associated with recalcitrant surface DOC, and a deep abyssal humic-like mixture.

Box model calculations have been performed for several cases of organic adsorption to illustrate the underly-
\end{abstract}

ing concepts. We then apply the framework to output from a global marine biogeochemistry model, by partitioning total dissolved organic carbon into several classes of macromolecules. Each class is represented by model compounds with physical and chemical properties based on existing laboratory data. This allows us to globally map the predicted organic mass fraction of the nascent submicron sea spray aerosol.

Predicted relationships between chlorophyll $a$ and organic fraction are similar to existing empirical parameterizations, but can vary between biologically productive and nonproductive regions, and seasonally within a given region. Major uncertainties include the bubble film thickness at bursting, and the variability of organic surfactant activity in the ocean, which is poorly constrained. In addition, polysaccharides may enter the aerosol more efficiently than Langmuir adsorption would suggest. Potential mechanisms for enrichment of polysaccharides in sea spray include the formation of marine colloidal particles that may be more efficiently swept up by rising bubbles, and cooperative adsorption of polysaccharides with proteins or lipids. These processes may make important contributions to the aerosol, but are not included here.

This organic fractionation framework is an initial step towards a closer linking of ocean biogeochemistry and aerosol chemical composition in Earth system models. Future work 
should focus on improving constraints on model parameters through new laboratory experiments or through empirical fitting to observed relationships in the real ocean and atmosphere, as well as on atmospheric implications of the variable composition of organic matter in sea spray.

\section{Introduction}

A growing body of observational evidence shows that the submicron sea spray aerosol is frequently dominated by organic material, attributable to a primary marine source from sea spray aerosol (SSA) (O'Dowd and de Leeuw, 2007; Facchini et al., 2008; Hawkins and Russell, 2010; Russell et al., 2010). The presence of organic matter in SSA may affect the atmospheric concentrations of cloud condensation nuclei $(\mathrm{CCN})$ in marine air, which in turn affect the radiative properties of clouds, and thereby also climate (Meskhidze and Nenes, 2006). A detailed review of the current state of research on marine organic aerosols can be found in Gantt and Meskhidze (2013).

Analysis of global climate model sensitivities shows that over remote ocean regions, cloud droplet number concentrations and cloud albedo can depend strongly on the simulated sea salt aerosol number concentration and hygroscopicity (Karydis et al., 2012; Moore et al., 2013). Several parameterizations for marine organic aerosol emissions have been proposed, all of which rely on empirical relationships with ocean chlorophyll $a$ concentrations ( $\operatorname{chl} a$ ) (O'Dowd et al., 2008; Fuentes et al., 2010b; Vignati et al., 2010; Gantt et al., 2011; Long et al., 2011). Thus, a key challenge in modeling the climate impacts of natural aerosols is the development of a process-based model to quantify the organic fraction of SSA (Carslaw et al., 2010). A process-based model will foster advances in understanding of the underlying drivers of marine POA (primary organic aerosol) emissions and their interactions with changes in global climate.

$\mathrm{Chl} a$ has been used as a basis for global atmospheric model parameterizations primarily because it is a globally available proxy for ocean biological activity. It is also moderately predictive of the organic aerosol fraction at sites such as Mace Head, Ireland (O'Dowd et al., 2004; Rinaldi et al., 2013), Point Reyes, California (Gantt et al., 2011), and Amsterdam Island (in the Southern Ocean) (Sciare et al., 2009), and more reliably so than other satellite-retrieved ocean color products such as dissolved organic carbon (DOC), particulate organic carbon (POC), and colored dissolved and detrital organic material (Gantt et al., 2011; Westervelt et al., 2012; Rinaldi et al., 2013). However, chl $a$ makes up only a tiny fraction of the available organic matter: estimates from satellite observations suggest that chlorophyll mass as a percentage of POC ranges from $<0.1 \%$ in ocean gyres to $>0.4 \%$ in biologically productive open ocean regions and reaches a maximum of about $2 \%$ in coastal waters (Gardner et al.,
2006). We use the terms "productive" and "nonproductive" to distinguish between ocean regions with and without currently active biological primary production, i.e., phytoplankton blooms, and the term "oligotrophic" to refer to regions where low nutrient availability results in low biological productivity for the entire year. Almost all of the marine OC (organic carbon) mass is dissolved organic matter (DOM), which is operationally defined as the portion of marine organic matter that will pass through a filter with a pore size of, e.g., $0.2-0.7 \mu \mathrm{m}$. The mass ratio of DOM : detritus : plankton in surface water is approximately $200: 10: 1$ (Verity et al., 2000; Nagata, 2008). It has been hypothesized that surfaceactive materials related to phytoplankton primary production and death drive the relationship between satellite-derived chl $a$ and sea spray OM (organic matter) (Long et al., 2011); this is supported by a correlation between marine chl $a$ and surfactant concentrations having been observed in situ during phytoplankton blooms as well as in laboratory phytoplankton cultures (Vojvodić and Ćosović, 1996; Gašparović and Ćosović, 2001, 2003).

Nevertheless, other evidence suggests that the positive correlation between chl $a$ and the marine aerosol fraction observed in bloom regions may not be representative for oligotrophic regions. In shipborne measurements in the North Atlantic, Russell et al. (2010) found a strong positive correlation $(0.91)$ of the submicron $\mathrm{OM}: \mathrm{Na}$ ratio with wind speed at $18 \mathrm{~m}$, and a moderate positive correlation (0.46) with $\operatorname{chl} a$. In the Arctic, they again found a strong positive correlation with wind speed (0.90), but a moderate negative correlation with chl $a$ (-0.63). Similarly, shipborne measurements during a period of high biological productivity in the open sea of the northeast Atlantic (Hultin et al., 2010) found a mild negative correlation between the marine aerosol organic fraction and chlorophyll $a$ in the water. During a cruise off the California coast, in spray aerosol artificially generated from natural waters, the organic aerosol mass fraction correlated positively with ocean DMS (dimethylsulfide), but not with chl $a$ (Bates et al., 2012). In a recent laboratory experiment, aerosol organic matter fractions in spray generated from breaking waves in a simulated phytoplankton bloom remained relatively constant during large changes in chl $a$ concentrations, but SSA hygroscopicity declined simultaneously with increases in heterotrophic bacteria concentrations (Collins et al., 2013; Prather et al., 2013).

These results suggest that empirical relationships with chl $a$ seasonal blooms are not adequate to predict the OM fraction of SSA, particularly outside of strong seasonal blooms. Indeed, a recent intercomparison of different parameterizations of the submicron marine organic aerosol found that parameterizations diverged most strongly in their simulation of the organic fraction in chlorophyll-poor regions, yet these regions, because of their large area, contributed the most to total global marine organic sea spray emissions (Albert et al., 2012). A careful reanalysis of the Mace Head measurements recently indicated that while chl $a$ is a better 
predictor of OM fraction in filter samples collected at Mace Head than satellite-derived DOM or POM, a time lag of ca. 8 days is observed between peaks in upwind ocean chl $a$ concentrations and OM enrichment in aerosol, suggesting that the timescales of biological processes in ocean surface waters should be taken into account in order to improve prediction (Rinaldi et al., 2013).

The challenge remains to develop a model framework capable of describing organic SSA enrichment both in regions of active phytoplankton primary production, and in less productive waters, and to explain how ocean chemistry affects enrichment. In this paper, we model the organic fraction of submicron sea spray aerosol as driven by the adsorption of macromolecules on bubble surfaces, mediated by molecular surface activity. At some times and locations, these functional relationships produce strong correlations with chl $a$, but under other circumstances the underlying biogeochemistry may differ so that the correlation with chl $a$ is much weaker, absent, or even negative. These differences highlight the need for incorporating a process-based model of ocean biota rather than relying on a single parameter such as chl $a$.

An initial presentation of some aspects of this approach was recently provided in Elliott et al. (2014), and a related paper will discuss ocean distributions of organic compound classes in greater detail (Ogunro et al., 2014).

In Sect. 2, we outline our aims and approach, and review observed patterns and broad patterns in the chemical composition and size distribution of sea spray aerosol. In Sect. 3, we introduce a novel framework for modeling the enrichment of organic matter in the submicron spray aerosol as a Langmuir adsorption process, and discuss possible chemical analogs for marine organic matter. In Sect. 4, we illustrate the aerosol enrichment predicted by the framework for single model compounds and for two-component mixtures. In Sect. 5, we combine the framework with distributions of marine organic macromolecules estimated from an ocean biogeochemistry model to generate an emission parameterization that can be applied in global circulation models. In Sect. 6, we further discuss our results, as well as the uncertainties and limitations inherent in this approach. In Sect. 7, we summarize our main findings and discuss implications for the further development of organic sea spray parameterizations.

\section{Effect of chemistry and particle size on enrichment}

\subsection{Aims and approach}

Our aim is to develop a process-based model that can capture broad geographic patterns in the amount and chemical composition of the organic fraction of marine aerosol using fields simulated by an ocean biogeochemistry model. To this end, it is necessary to partition the marine organic matter into several classes of compounds which may differ in their physical and chemical characteristics. We have chosen five broad classes of macromolecules: a lipid-like mixture associated with labile DOC, a polysaccharide-like mixture associated primarily with semilabile DOC, a proteinlike mixture with concentrations intermediate between lipids and polysaccharides, a processed mixture associated with recalcitrant surface DOC (Hansell, 2013), and a deep abyssal humic-like mixture that is brought to the surface by convective overturning. For brevity, we will refer to these classes as lipids (Lip), polysaccharides (Poly), proteins (Prot), processed (Proc), and humics (Hum), but we recognize that this usage is not a precise classification and further clarification of the chemical nature of the classes will be the subject of future work. For each class of macromolecules, we adopt a single organic molecule as a proxy for the adsorption behavior of each group at the air-water interface. This allows for an approximation of the changes in chemical composition that occur as freshly injected DOC is gradually biologically and chemically modified.

Empirical studies of fresh phytoplankton blooms suggest that the approximate distribution of carbon mass in the phytoplankton is $60: 20: 20$ between proteins, polysaccharides and lipids, respectively, and this is reflected upon injection 2.1. Because lipids are more quickly removed or altered by chemical and biological processes, their ocean concentrations are much smaller, yet their surface affinity and enrichment is higher than for the other groups. Proteins are present in higher concentrations, but are somewhat less strongly enriched than lipids. Polysaccharide concentrations are higher than those of proteins and lipids, but have the lowest adsorption surface affinity. Humics represent abyssal compounds that are mixed into the ocean surface layer during deep overturning. Processed compounds correspond to the recalcitrant portion of DOC, including molecules that have undergone chemical degradation and recombination. However, less emphasis will be placed on these classes, because their surface activity is generally low.

These macromolecule classes are then implemented into a modeling framework that predicts the submicron SSA organic mass fraction by assuming that multiple classes of compounds may compete for bubble surface area and establish equilibrium according to the Langmuir adsorption isotherm. The properties of the compound classes and their mapping to variables from an ocean biogeochemistry model will be discussed in detail in Sec. 5.2, but the general outline is as follows.

Further development will be required to better constrain the model and refine the partitioning of DOC. Nevertheless, we will show that this approach is capable of reproducing important features of the observed patterns in the SSA organic mass fraction. In particular, the model predicts that OM fractions are relatively constant across most of the globe at most times, but also approximately reproduces the increased OM fraction during strong, highly localized seasonal phytoplankton blooms associated with high $\operatorname{chl} a$, e.g., in the North At- 
lantic. Unlike in previous parameterizations, chl $a$ is not directly used to calculate the OM fraction, and so the model produces strong positive correlations between seasonal cycles in OM fraction and chl $a$ in certain localized blooms, but these relationships cannot be extrapolated globally. In addition, the model predicts differences in the detailed chemical composition of the organic aerosol in the different regions, which may provide an explanation for observed differences between the organic aerosol composition in the Arctic and the North Atlantic.

In drawing ties between ocean biogeochemistry and atmospheric aerosol chemistry, we utilize notation common in each field. In particular, we draw the reader's attention to the fact that we will express quantities of organic mass (OM) and OC in different units depending on the context. In the atmospheric context, we will generally use units of mass or mass concentration, which is how organic mass quantities are typically reported in the atmospheric chemistry literature. In the ocean context, we will generally use the molar concentration of carbon atoms in the organic matter $\left(\mu \mathrm{mol} \mathrm{OC} \mathrm{L}^{-1}\right.$ or similar), which is the convention of most ocean biogeochemistry observations and models. Mass of OM can be converted to moles of OC by multiplication with the factor: $\left(\frac{m_{\mathrm{OM}}}{m_{\mathrm{OC}}}\right)_{i} \cdot \frac{M_{\mathrm{C}}}{M_{i}}$.

\subsection{Conceptual overview}

In the open ocean, sea spray particles originate primarily from the bursting of bubbles produced from wave-breaking (Lewis and Schwartz, 2004). As bubbles rise through the water column, surface-active dissolved and particulate materials accumulate on the bubble surface (Blanchard, 1975).

The deposition of collected material at the air-water interface contributes to the formation of the sea-surface microlayer (SML), a chemically distinct film that is enriched in surface-active organic matter relative to the underlying bulk water (Wurl and Holmes, 2008; Wurl et al., 2011; Cunliffe et al., 2012). The SML is disrupted by breaking waves, but reforms within a few seconds and is generally sustained when wind speeds are less than $10 \mathrm{~m} \mathrm{~s}^{-1}$. Bubbles rest on the ocean surface for a period of up to a few seconds or more before bursting, which can be prolonged by the presence of soluble surfactant compounds (Garrett, 1967; Johnson and Wangersky, 1987; Modini et al., 2013).

Upon bursting, the film disintegrates into film drops (typically up to ca. 20 drops, but potentially many dozens, depending on bubble size, Blanchard and Syzdek, 1982, 1988; Resch and Afeti, 1992; Spiel, 1998). The film drops make up the majority of the submicron spray aerosol, and because they are drawn form the bubble film, they are enriched in surface-active organic matter (Macintyre, 1970; Blanchard, 1989). A bursting bubble also produces up to about seven jet drops (Spiel, 1994, 1997), the material for which is drawn primarily from the underlying bulk water; jet drops are therefore far less strongly enriched with the organics that coat the bubble surface. A conceptual overview of the processes

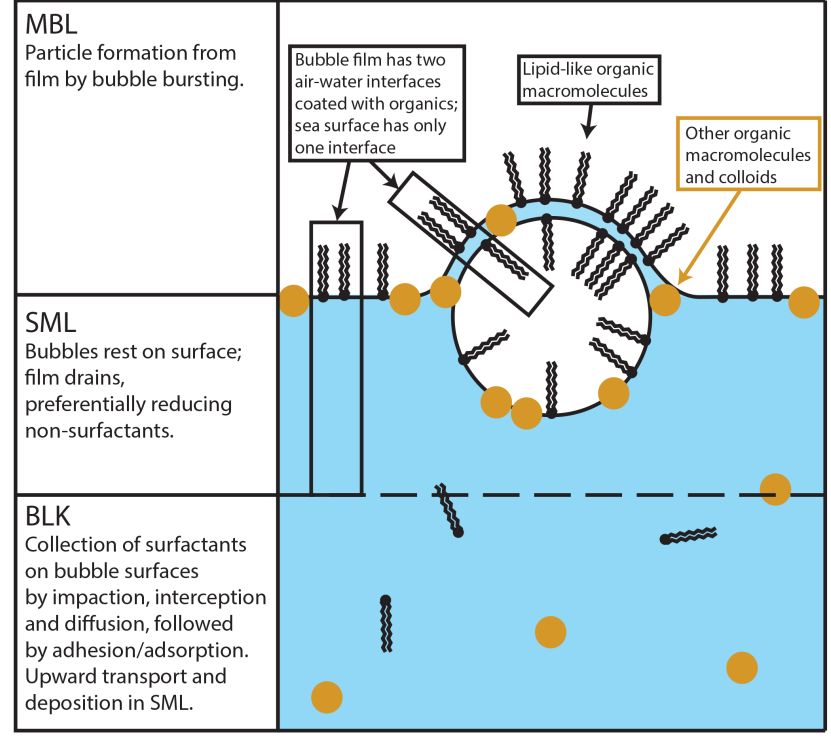

Figure 1. Conceptual schematic of bulk water (BLK), SML, and MBL aerosol enrichment processes.

leading to enrichment of organic matter in aerosol is shown in Fig. 1. In the remainder of this paper, we will consider only the composition of the freshly formed film drops, which roughly corresponds to the composition of the submicron sea spray.

The enrichment of organics in the SML and bubble film also will depend on the thickness of the film. SML sampling thicknesses range from 20 to $400 \mu \mathrm{m}$ depending on the sampling method used (Cunliffe et al., 2012), while bubble film thicknesses range from 0.01 to $1 \mu \mathrm{m}$ (Modini et al., 2013). In a simple conceptual model in which all organics are partitioned to the surface of a "slab" of saltwater or to both the inner and outer surfaces of a bubble film, the organic enrichment would be significantly higher for the thinner bubble films than for the thicker SML sample. This would provide a mechanism that would explain the observations indicating that the OC: Na mass ratio is $10^{2}-10^{3}$ higher in the submicron MBL (marine boundary layer) aerosol than in the SML (Russell et al., 2010).

\subsection{Enrichment factor}

In this paper, we define the enrichment factor $F_{i, j}$ of the $i$ th chemical component in the $j$ th mode (SML or bubble film) as

$F_{i, j}=\frac{m_{i, j} / m_{\mathrm{Na}, j}}{m_{i, \mathrm{blk}} / m_{\mathrm{Na}, \mathrm{blk}}} \approx \frac{m_{i, j} / m_{\mathrm{SS}, j}}{m_{i, \mathrm{blk}} / m_{\mathrm{SS}, \mathrm{blk}}}$,

where the $m_{i, j}\left(\mathrm{~kg} \mathrm{~kg}^{-1}\right)$ are the mass mixing ratios of the respective solution constituents, the subscript "blk" denotes the bulk water, and the subscript "SS" denotes sea salt. Because the submicron aerosol is primarily drawn from film drops, we assume that the bubble film fraction is predictive 
of the organic fraction in submicron nascent spray. This assumption is supported by, e.g., recent studies showing the chemical similarity of a wave flume surface and the particles produced from that surface (Ebben et al., 2013), as well as more generally supported by the observation that submicron spray is produced primarily from film drops (Blanchard and Syzdek, 1982, 1988; Resch and Afeti, 1992; Spiel, 1998). Note that sea salt mass may be altered during atmospheric transport, e.g., due to chlorine depletion by acid substitution in $\mathrm{MBL}$ aerosol, the ratio of $\mathrm{Na}: \mathrm{Cl}$ mass in marine aerosol can be several times higher than in seawater (Pszenny et al., 1993; Keene et al., 1998; Buseck and Posfai, 1999; Lewis and Schwartz, 2004), but the equality should hold for nascent spray. Oxidation of organic matter may also occur in the atmosphere, increasing the organic mass content.

Reported enrichment factors for organic matter in marine aerosol vary over a range greater than 10-1000 (Burrows et al., 2013) and are generally not directly comparable, due to the lack of a standardized definition. However, a few general trends can be observed:

1. Surfactants that are enriched in the SML are also further enriched in the aerosol (Kuznetsova et al., 2004, 2005; Russell et al., 2010), and experimental evidence indicates that the transport of surfactants from seawater to the aerosol is linearly related to the transport to the seawater surface (Tseng et al., 1992). This suggests that the same chemico-physical properties underlie both enrichment steps.

2. SML enrichment is strongest when bulk surfactant concentrations are low; when bulk surfactant concentrations are comparatively high, additional increases in bulk concentrations result in proportionally smaller increases in surface coverage (Marty et al., 1988; Hultin et al., 2011; Wurl et al., 2011). This is consistent with a surface saturation effect: as concentrations increase, more molecules compete for a smaller available surface area.

3. At high enrichment, adsorbing molecules compete for surface area at the air-water interface, with the most surface-active compounds crowding out less surfaceactive molecules (Jarvis et al., 1967; Garrett, 1968; Harper and Allen, 2007).

4. Within a single homologous chemical group, enrichment of the particulate fraction is typically stronger than enrichment of the dissolved fraction (Marty et al., 1988; Kuznetsova and Lee, 2002; Kuznetsova et al., 2005). This is likely because bubbles more efficiently scavenge larger particles due to their larger radius and inertia (Sutherland, 1948; Weber et al., 1983; Dai et al., 1998, 2000).

\section{Competitive Langmuir adsorption model}

\subsection{Model equations}

To represent the saturation effect and the chemical and physical specificity of enrichment, we model the surface coverage as a competitive Langmuir adsorption equilibrium (Langmuir, 1918):

$\theta_{i}=\frac{\Gamma_{i, \mathrm{eq}}}{\Gamma_{i, \infty}}=\frac{\alpha_{i} C_{i}}{1+\sum_{i^{\prime}} \alpha_{i^{\prime}} C_{i^{\prime}}}$,

where the subscript $i$ indicates the $i$ th component of the mixture, $\theta_{i}$ is the fractional surface coverage, $C_{i}$ is the molar concentration, $\alpha_{i}$ is the Langmuir coefficient, $\Gamma_{i, \text { eq }}$ is the equilibrium surface excess and $\Gamma_{i, \infty}$ is the saturation surface excess.

Substantial experimental evidence supports the application of the Langmuir isotherm to the adsorption of surfactants onto the surface of bubbles ascending through the water column, and at the air-water interface (e.g., Skop et al., 1994; Giribabu and Ghosh, 2007; Schmitt-Kopplin et al., 2012). Fuentes et al. (2010a) have applied the Langmuir isotherm to fit laboratory measurements of surface-area tension relationships for phytoplankton exudate samples used to generate laboratory aerosol. Long et al. (2011) used a Langmuirbased equation in a global model parameterization of the organic fractionation of sea spray, but with a different formulation than we propose here, and using chl $a$ as the driving variable.

Potential interactions between molecules at the surface, e.g., cooperative adsorption (Baeza et al., 2005), are neglected. Importantly, this implies that Langmuir coefficients can be linearly combined: we can define an effective bulk Langmuir coefficient, $\alpha_{\text {eff }}$, as a concentration-weighted average of the $\alpha_{i}$ :

$$
\begin{aligned}
\sum_{i} \theta_{i} & =\frac{\alpha_{\mathrm{eff}} C_{\mathrm{tot}}}{1+\alpha_{\mathrm{eff}} C_{\mathrm{tot}}}, \\
C_{\mathrm{tot}} & =\sum_{i} C_{i}, \\
\alpha_{\mathrm{eff}} & =\frac{\sum_{i} \alpha_{i} C_{i}}{C_{\mathrm{tot}}} .
\end{aligned}
$$

In other words, if the enrichment of each member of a group of compounds is described by the competitive Langmuir isotherm (Eq. 2), it follows that the enrichment of the entire group can also be described by the Langmuir isotherm (Eq. 5). This justifies the simplification of representing a complex mixture of compounds as a single class.

The Langmuir isotherm allows for three of the effects observed in enrichment of the SML and aerosol (Sect. 2.3): stronger enrichment of more surface-active molecules, saturation, and competition between constituents. The fourth effect, stronger particulate enrichment, can be added as a simple extension by using a higher value of $\alpha_{i}$ for particulates than for dissolved matter. 


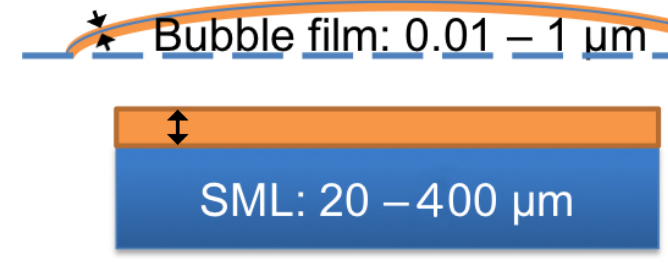

Figure 2. Cartoon of the slab model used for calculation of the enrichment ratio from surface coverage. The bubble film, when resting at the water surface as suggested by the dashed blue line, is partially coated on both sides with organic surface-active materials, while the SML is partially coated on only one side. Bubble film thicknesses range from about 0.01 to $1 \mu \mathrm{m}$ (Modini et al., 2013). SML sampling thicknesses depend upon the sampling method and range from 20 to $400 \mu \mathrm{m}$ (Cunliffe et al., 2012).

To calculate the organic mass fraction of the bubble film, we treat the surface as a slab of seawater of thickness $l_{\text {bub }}$ that is partially coated with surfactants with fractional sur-

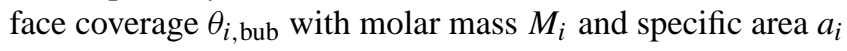
(Fig. 2). The mass enrichment factor is then

$F_{i, \mathrm{bub}, \text { mass }}=\left[\frac{n_{j} \frac{\theta_{i, \mathrm{bub}} M_{i}}{a_{i}}}{\rho_{\mathrm{SW}} \cdot l_{j} \cdot s}\right]\left[\frac{s}{m_{i, \mathrm{blk}}}\right]$,

where $s=0.035 \mathrm{~kg} \mathrm{~kg}^{-1}$ is the ocean salinity, and $\rho_{\mathrm{SW}}=1.025 \mathrm{~kg} \mathrm{~L}^{-1}$ is the approximate density of seawater. We have assumed that the concentration of the organic material in the bulk is negligible, and neglected effects of bubble curvature. The parameter $n_{\text {bub }}$ is an adjustable parameter that represents the number of sides of the bubble film that are covered with the areal fraction $\theta_{\text {bub. }}$. The smallest physically meaningful value, $n_{\text {bub }}=1$, implies that only the bubble interior is coated. We assume $n_{\text {bub }}=2$, which implies that the coverage of the interior and exterior films of the bubble are equivalent (Fig. 2). Values of $n_{\text {bub }}>2$ would imply an enriched microlayer, which is possible under calm conditions.

The dry mass fraction in the nascent aerosol is given by

$$
\left(\frac{m_{i, \mathrm{bub}}}{m_{i, \mathrm{bub}}+m_{\mathrm{NaCl}}}\right)=\frac{n_{j} \frac{\theta_{i, \mathrm{bub}} M_{i}}{a_{i}}}{n_{j} \frac{\theta_{i, \mathrm{bub}} M_{i}}{a_{i}}+\rho_{\mathrm{SW}} \cdot l_{j} \cdot s} .
$$

For the SML, the layer thickness is the sampling thickness, which ranges between 20 and $400 \mu \mathrm{m}$ for sampling devices in use today (Cunliffe et al., 2012). For the bubble film, we take the mean film thickness to be $0.1 \mu \mathrm{m}$. Because soluble surfactants can stabilize the bubble cap (Garrett, 1967; Johnson and Wangersky, 1987), bubbles with high surfactant coverage persist longer and more drainage occurs before bursting. Stabilized bubbles can be as thin as $0.1 \mu \mathrm{m}$, while clean bubbles can have thicknesses of up to a few microns, depending on bubble diameter (Spiel, 1998; Modini et al., 2013).
The slab model can account to a large extent for the fact that enrichment factors observed in the atmospheric aerosol are typically 5-20 times higher than in the SML (Kuznetsova et al., 2004, 2005). It may also account in part for the size distribution of the organic mass fraction: since smaller film drop particles are more frequently produced from the thinner films of smaller bubbles (Spiel, 1998), they would be expected to have a higher organic enrichment than larger particles produced from the thicker films of larger bubbles (Oppo et al., 1999; Facchini et al., 2008; Gantt et al., 2011). Experiments with radio-labeled lipids in artificial seawater have also shown that smaller bubbles transport surfactants to the air more efficiently than larger bubbles (Tseng et al., 1992).

We illustrate the relationship between the organic mass fraction and enrichment ratio in Fig. 3, which shows the organic mass fractions in the nascent film aerosol (after subtracting water mass), calculated as a function of marine bulk OC concentrations and bulk : MBL OC enrichment factors.

Bulk OC : $\mathrm{NaCl}$ ratios of $10^{-4}-10^{-3}$ (Ittekkot, 1982; Carlson et al., 2000; Lomas et al., 2001), combined with organic mass fractions of ca. $0.2-0.3$ in the submicron aerosol over the remote open ocean, imply that enrichment factors for the submicron SSA are from about $10^{2}$ to over $10^{3}$ (Russell et al., 2010). Much higher organic mass fractions (up to ca. 0.8) have been observed for the smallest particle sizes at Mace Head downwind of seasonal blooms (O'Dowd et al., 2004; Facchini et al., 2008; Gantt et al., 2011). However, the enrichment factor is highly sensitive to the size fraction selected: integrating the size distribution of the organic fraction from artificially generated aerosol (Gantt et al., 2011) across a canonical sea spray size distribution (Lewis and Schwartz, 2004) results in an organic mass fraction of ca. $60 \%$ for $D_{\mathrm{p}}<0.5 \mu \mathrm{m}$, but only ca. $15 \%$ for $D_{\mathrm{p}}<1 \mu \mathrm{m}$ and $3 \%$ for $D_{\mathrm{p}}<2 \mu \mathrm{m}$.

The model requires that the following physical parameters be specified for each of the components: Langmuir coefficient $\alpha_{i}$, specific area $a_{i}$, and molecular mass $M_{i}$. In addition, it requires specification of the bubble film thickness $l_{\text {bub }}$ for the calculation of the enrichment ratio, and $n_{\text {bub }}$, which controls the fractional coating of the exterior surface relative to the interior surface. These parameters can be estimated either from laboratory experiments on individual model compounds or empirically fitted to observations of observed organic mass fractions.

\subsection{Selected model compounds and their chemical properties}

\subsubsection{Overview of data reviewed}

A large number of experiments have been published that include adsorption data at the air-water interface under a variety of conditions (e.g., Adamson and Gast, 1997). Most of these experiments were conducted at room temperature, which may not be representative for cold sea-surface temper- 


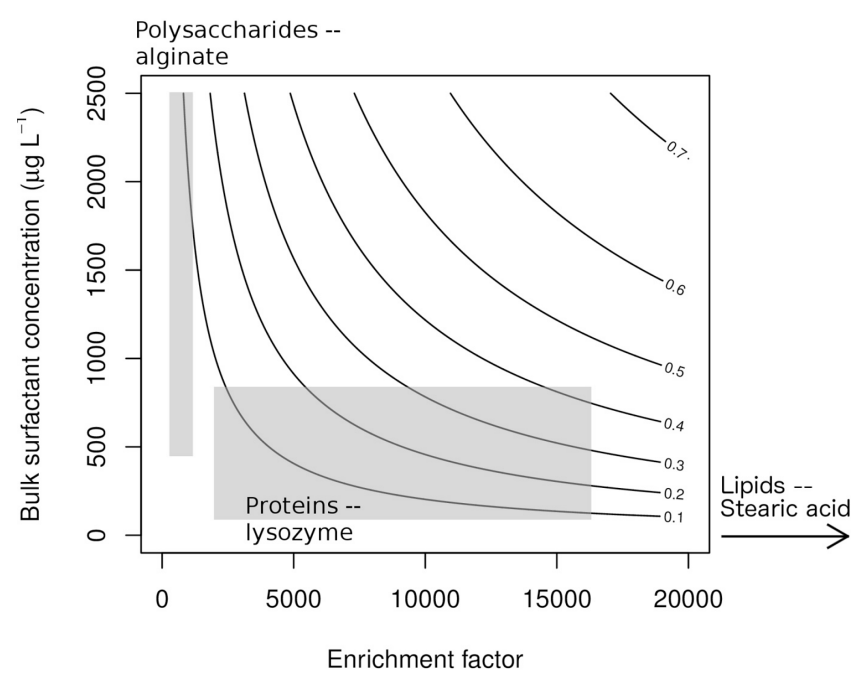

Figure 3. Organic mass fraction in dry aerosol $(\mathrm{OM}:(\mathrm{NaCl}+\mathrm{OM})$ mass ratio), as a function of enrichment factor and ocean organic mass. Approximate ranges of mass and enrichment factors for polysaccharides and proteins, as defined in Sect. 3.2 and Sect. 5.2, are indicated as gray shaded regions. Lipids would appear far to the right of the figure, near the bottom.

ature polar regions. Salinity varies between experiments but was lower than the salinity of seawater in most cases. Nevertheless, a substantial number of studies report the adsorption behavior of organic macromolecules under conditions approximating the marine surface environment. We have summarized these studies in Table 1.

For each of the organic classes in our study, we have selected representative analog molecules for which such measurements are available. Based on the literature we reviewed, we select order-of-magnitude estimates of the Langmuir half-saturation and surface excess parameters for each ana$\log$ molecule (Table 1).

The maximum surface excess $\Gamma_{\max }$ can be obtained by nonlinear curve fitting to the Langmuir-LangmuirSzyszkowski equation (Lan et al., 2001; Svenningsson et al., 2006). $\Gamma_{\max }$ can be approximately understood as the inverse of the area occupied per unit of substance, when the surface is saturated. Surface excess is less variable than the Langmuir adsorption parameter, for our model compounds. Although the geometric arrangement and orientation of molecules on the surface can differ widely between molecules, variations in $\Gamma_{\max }$ rarely exceed an order of magnitude within a homologous series (Graham and Phillips, 1979a, b; Damodaran and Razumovsky, 2003; Tuckermann, 2007).

We now discuss in detail the analogs recommended for each class of macromolecule.

\subsubsection{Proteins}

We include two analog proteins: lysozyme, a globular protein composed of 100 amino acid residues, and casein, a disordered protein that is highly surface-active (Adamson and Gast, 1997; Damodaran and Razumovsky, 2003). These model compounds are representative of a range of surface activities that are observed in marine phytoplankton blooms (Ẑutić et al., 1981; Barger and Means, 1985). We consider lysozyme and BSA (bovine serum albumin) to represent freshly released enzymes, which should temporarily retain their structure after injection into the water column. Casein, however, is taken to be representative of the surface behavior of a denatured protein (Lehninger, 1975; Benner, 2002). The proteins adsorb by training monomeric sequences along the interface with hydrophobic groups rotated into the vapor phase, then looping as necessary, with the result that disordered and denatured proteins tend to have a stronger surface affinity than structured, globular proteins (Graham and Phillips, 1979a; Adamson and Gast, 1997; Baeza et al., 2005).

\subsubsection{Polysaccharides}

Soluble starches are traditionally considered the representative model for carbohydrates derived from phytoplankton (Van Vleet and Williams, 1983; Frew, 1997). Naturally occurring polysaccharides are typically water-soluble and not surface-active (Stephen, 1995). We adopt three polysaccharide analogs: pectin, alginate and maltodextrin. Pectin is a structural component of cell walls in fruit and a well-studied polysaccharide of natural, intermediate amphiphilicity (Nilsson and Bergenståhl, 2006; Perez et al., 2011). Alginate may be derived from brown algae such as Macrocystis. It is commercially available and its surface activity is similar to that of pectin (Babak et al., 2000). Maltodextrin is a synthetic oligomer (Shogren and Biresaw, 2007), consisting of only about 10-20 glucose subunits linked by regular glycosidic bonds, which has very limited surface activity.

\subsubsection{Lipids}

Atmospheric aerosol chemists have frequently used sodium dodecyl sulfate (SDS) as a proxy for natural lipids. However, SDS is more soluble and has lower affinity for the air-water interface than representative lipids found in the environment, such as the analogs we have selected: stearic acid, oleic acid, and cholesterol. Multiple lines of experimental evidence indicate very high surface activity of these compounds. Diffusion from surface films into the bulk phase is slow (Sebba and Briscoe, 1940; Heikkila et al., 1970). For oleic and stearic acid, results from theory describing polymer dissolution (Ter Minassian-Saraga, 1956; Brzozowska et al., 2012) and measurements of diffusion coefficients for long aliphatic chain molecules justify a very high estimate of surface activity, 
Table 1. Marine and laboratory model compounds selected to represent the ocean macromolecules, along with reference half-saturation concentrations $C_{1 / 2}$ and carbon surface excess $\Gamma_{\max }$. Except as stated in the text, data are for room temperature and low ionic strength. Concentrations and surface densities are given in moles per liter of carbon and then atoms per square ångström. Parenthetical values were estimated based on others in the same class. We use the following abbreviations in the table: proteins (Prot), polysaccharides (Poly), lipids (Lip), humic acid and related compounds (Hum).

\begin{tabular}{lllrrl}
\hline \multirow{2}{*}{ Structure } & $\begin{array}{l}\text { Ocean } \\
\text { analogs }\end{array}$ & $\begin{array}{l}\text { Laboratory } \\
\text { analogs }\end{array}$ & $C_{1 / 2}$ & Carbon $\Gamma_{\max }$ & References \\
\hline \multirow{2}{*}{ Prot } & Generic enzymes & Lysozyme & $10^{-4}$ & 1.0 & F97, GP79b \\
& Denatured strands & Casein & $10^{-5}$ & 0.5 & BM85, DR03, GP79b \\
\hline \multirow{2}{*}{ Poly } & Soluble starch & Maltodextrin & $>10^{0}$ & $(10-100)$ & SB07, VW83 \\
& Alginate & Natural alginate & $10^{-1}$ & $10-100$ & B00, VW83, Z81 \\
& Generic glucans & Pectin & $10^{-1}$ & Close packing & F97, NB06, RB00, P11 \\
& & Gum arabic & $10^{-2}$ & 50 & DR03, G91, NB06 \\
\hline \multirow{2}{*}{ Lip } & Commercial surrogate & SDS & $10^{-2}$ & 0.2 & CT52, L98, T70, T07 \\
& C18 fatty acids & Stearic and oleic & $<10^{-6}$ & 1.0 & B12, CD68, H70, G70, L91 \\
& Sterols & Cholesterol & $<10^{-6}$ & 0.7 & A86, BM85, MB78, P88, P05 \\
\hline \multirow{2}{*}{ Hum } & Fulvic acid & Riverine standard & $10^{-1}$ & 1.0 & A89, D06, S06, T07, VW83 \\
& Humic acid & Commercial & $10^{-1}$ & 1.0 & M90, T07, TC04 \\
\hline
\end{tabular}

General abbreviations: BSA - bovine serum albumin, SDS - sodium dodecyl sulfate. Reference abbreviations: A86 - Alexander et al. (1986); A89 Averett et al. (1989); B00 - Babak et al. (2000); B12 - Brzozowska et al. (2012); BM85 - Barger and Means (1985); CD68 - Christodoulou and Rosano (1968); CT52 - Cook and Talbot (1952); D06 - Dinar et al. (2006); DR03 - Damodaran and Razumovsky (2003); F97 - Frew (1997); G70 - Garrett (1970); G91 - Gaonkar (1991); H70 - Heikkila et al. (1970); L91 - Lindsley et al. (1991); L98 - Li et al. (1998); M90 - Malcolm (1990); MB78 -

McGregor and Barnes (1978); NB06 - Nilsson and Bergenståhl (2006); P88 - Parrish (1988); P05 - Parra-Barraza et al. (2005); P11 - Perez et al. (2011); RB00 - Rosilio and Baszkin (2000); S06 - Svenningsson et al. (2006); SB07 - Shogren and Biresaw (2007); T70 - Tajima et al. (1970); T07 -

Tuckermann (2007); TC04 - Tuckermann and Cammenga (2004); VW83 - Van Vleet and Williams (1983); Z81 - Ẑutić et al. (1981).

with $C_{1 / 2}<10^{-6}$ (Wilke and Chang, 1955; Sallee and Dietschy, 1973; Weisiger and Zucker, 2002).

This is consistent with the extremely low solubility measured for long-chain lipids (Vorum et al., 1992). Cholesterol is likewise highly surface-active and sparingly soluble (Sebba and Briscoe, 1940; McGregor and Barnes, 1978; Alexander et al., 1986).

\subsubsection{Processed compounds}

The processed and mixed organics include those resulting from biogeochemical aging of the other groups, i.e., they represent the recalcitrant portion of DOC. Some of the freshly produced polymers hydrolyze after being released via cell disruption into seawater, and they are further degraded by enzymes, bacteria, and photolysis (Tranvik and Kokalj, 1998). Fragments may recombine into new molecules with a heterogenous mixture of functional groups (Amon and Benner, 1996; Benner, 2002).

The identity and surface adsorption behavior of these processed compounds is poorly characterized. Lacking better information, we take them to be most similar to the humics and apply the same adsorption parameters.

\subsubsection{Humics}

The reviewed literature values for humics refer primarily to material derived from riverine and coastal sources and some- times available commercially as a set of standard substances, e.g., Suwannee River fulvic acid or European counterparts (Van Vleet and Williams, 1983; Averett et al., 1989; Tuckermann and Cammenga, 2004; Svenningsson et al., 2006). Langmuir adsorption parameters are fairly consistent across these studies, so that some confidence can be attached to the values in Table 1.

\section{Box model calculations}

To illustrate the concepts developed here, we performed box model calculations for individual compounds and twocomponent systems. The values used for the model parameters are listed in Table 2; we will refer to this set of values as the BASE case. Here we present the organic enrichment of the submicron aerosol, as calculated by the box model, for single compounds and for two-component systems. Each result is shown across the approximate range of surface concentrations of the respective macromolecular class that are present in the results of global ocean biogeochemical model calculations. The global ocean biogeochemical model will be described in detail in Sect. 5.

\subsection{Single model compounds}

In Fig. 4, we show the organic mass fraction resulting from each of several model macromolecules, and illustrate its sen- 
(a) Stearic acid

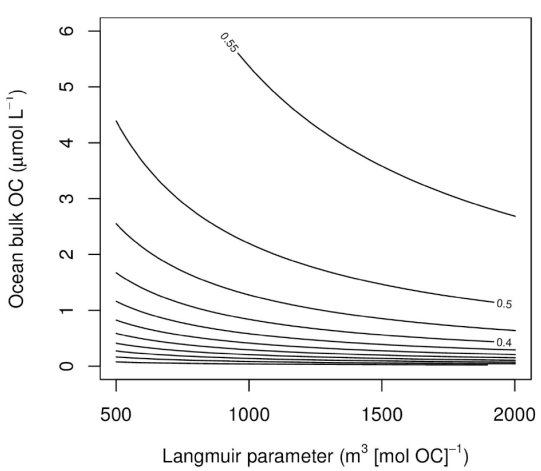

(c) Alginate

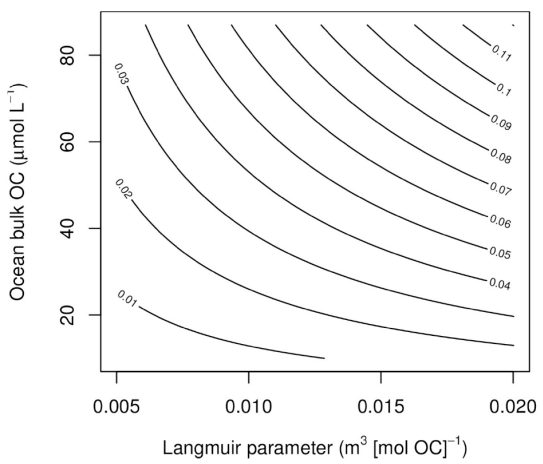

(b) Lysozyme

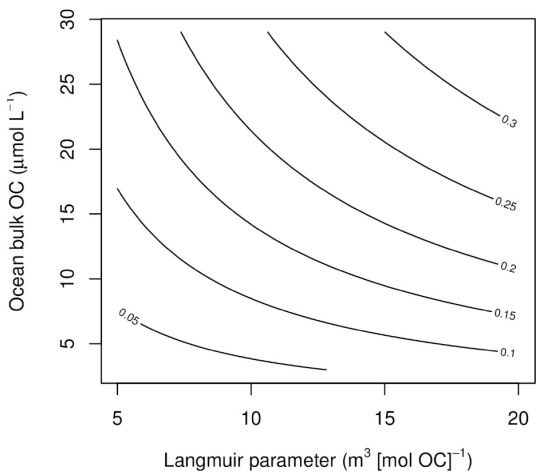

(d) Suwannee River fulvic acid

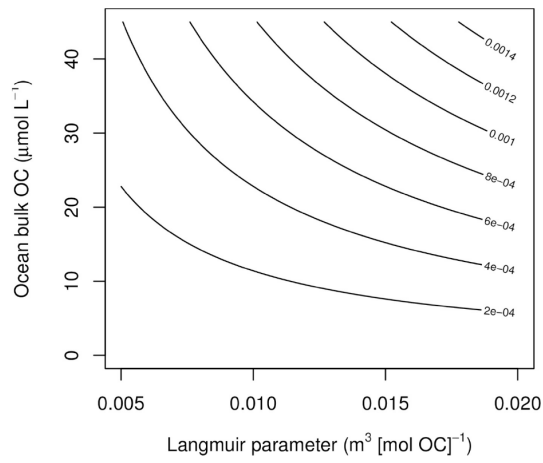

Figure 4. Organic mass fraction in dry aerosol $(\mathrm{OM}:(\mathrm{NaCl}+\mathrm{OM})$ mass ratio), predicted organic mass fractions for model compounds as a function of Langmuir parameter $\alpha_{i}\left(\mathrm{~m}^{3}(\mathrm{~mol} \mathrm{OC})^{-1}\right)$ and OC molar concentration. Ranges of OC concentration (vertical axis) are estimated for classes of molecules from ocean biogeochemical model output, as described in Sect. 5, and chemical parameters are as indicated in Table 2. Ranges of Langmuir parameters (horizontal axis) are obtained by varying $\alpha_{i}$ between 0.5 and 2 times the respective model compound value from the BASE case.

Table 2. Coefficients used to calculate box-model and global organic enrichment (BASE case). Values are derived from model compounds as described in Table 1: lysozyme, natural alginate, stearic acid, fulvic acid.

\begin{tabular}{|c|c|c|c|c|c|c|c|}
\hline $\begin{array}{l}\text { Compound } \\
\text { class }\end{array}$ & $\begin{array}{l}\text { OM : OC } \\
\text { ratio }\end{array}$ & $\begin{array}{c}C_{1 / 2} \\
\left(\mathrm{~mol} \mathrm{C} \mathrm{L}^{-1}\right)\end{array}$ & $\left(\mathrm{m}^{3} \mathrm{~mol}^{-1}\right)$ & $\begin{array}{c}M_{i} \\
\left(\mathrm{~g} \mathrm{~mol}^{-1}\right)\end{array}$ & $\begin{array}{c}a_{i} \\
\left(\AA^{2} \text { molec. }^{-1}\right)\end{array}$ & $\begin{array}{c}M_{i} / a_{i} \\
\left(\mathrm{mg} \mathrm{m}^{-2}\right)\end{array}$ & References \\
\hline Polysaccharides & 2.3 & 0.1 & 9.0 & 250000 & 300 & 140 & $\begin{array}{l}\text { B00, F01, SB07, } \\
\text { P11, TL01 }\end{array}$ \\
\hline Proteins & 2.2 & $1.0 \times 10^{-4}$ & 22000 & 66463 & 4400 & 2.5 & B02, F01, GP79a \\
\hline Lipids & 1.3 & $1.0 \times 10^{-6}$ & 18000 & 288 & 18 & 2.6 & B12, H70, TL01 \\
\hline Humics & 1.8 & 0.1 & 0.40 & 732 & 34 & 3.6 & A89, M90, S06 \\
\hline Processed & 1.8 & 0.1 & 0.40 & 732 & 34 & 3.6 & $\begin{array}{l}\text { А89, B00, } \\
\text { M08, S06 }\end{array}$ \\
\hline
\end{tabular}

Reference abbreviations: A89 - Averett et al. (1989); B00 - Babak et al. (2000); B02 - Benner (2002); B12 - Brzozowska et al. (2012); F01 - Fraga (2001); GP79a Graham and Phillips (1979a); H70 - Heikkila et al. (1970); M90 - Malcolm (1990); M08 - Moore et al. (2008); P11 - Perez et al. (2011); S06 - Svenningsson et al. (2006); SB07 - Shogren and Biresaw (2007); TL03 - Turpin and Lim (2001). 
sitivity to bulk concentrations of the macromolecule, and to variations in the Langmuir adsorption parameter. The compounds shown here are a representative lipid (stearic acid), protein (lysozyme), polysaccharide (alginate) and humic compounds (Suwannee River fulvic acid).

Among the macromolecular analogs shown in Fig. 4, only stearic acid and lysozyme are sufficiently surface-active to contribute significantly to the mass fraction of the film. Stearic acid contributes the most, despite the fact that the lipids are present in far lower concentrations than the other macromolecular classes, because of its strong affinity for the air-water interface. By contrast, humics (Suwannee River fulvic acid) can be present in much higher concentrations in the bulk ocean water, but contribute negligibly to the film. Polysaccharides would contribute negligibly using alginate as the model compound, but other models such as casein have stronger surface activity.

\subsection{Two-component model}

We now illustrate the effect of competitive adsorption in a two-component model consisting of a lipid (stearic acid) and a protein (lysozyme or casein), with properties as specified in Tables 1 and 2. The model representations of lysozyme and casein differ only in the value of $\alpha_{i}$, which is 10 times greater for casein than for lysozyme.

Stearic-acid-like lipids dominate the surface adsorption when they are present in a mixture with globular, lysozymelike proteins (Fig. 5a). Disordered, casein-like proteins have higher surface activity. While still less adsorptive than stearic acid, they are highly competitive as a result of their higher marine concentrations (Fig. 5b).

\section{Ocean biogeochemical model}

\subsection{Description of simulations}

Marine biogeochemical systems models now incorporate major processes determining the distribution of organic material in the ocean. These include the release and transport of labile and semilabile DOC (Moore et al., 2001, 2004; Hansell et al., 2012), which have e-folding lifetimes in surface waters of approximately 10 and 100 days, respectively, before being removed by microbial processes (e.g., consumption by heterotrophic bacteria, Christian and Anderson, 2002) or transformed by photochemical reactions (Tranvik and Kokalj, 1998).

We used the Parallel Ocean Program (POP; Maltrud et al., 1998) to simulate the general circulation and its biogeochemical elemental cycling (BEC) routines (Moore et al., 2004) to simulate marine biogeochemistry. Both are components of the Community Earth System Model (CESM; http://www2.cesm.ucar.edu, Hurrell et al., 2013). Calculations were performed using the CESM 1.0 beta release 11 . Biogeochemistry variables calculated in BEC include sev- eral classes of nutrients, phytoplankton, and zooplankton, in addition to dissolved inorganic carbon (DIC), alkalinity, POC and semilabile DOC. Biogeochemical tracers are transported, and their concentrations are updated in each time step by a tendency that includes source, removal, advection, and diffusion terms as in Gregg et al. (2003), Sarmiento and Gruber (2006), and Elliott et al. (2011):

$\frac{\partial}{\partial t} T_{k}=\nabla \cdot\left(D \nabla T_{k}\right)-\boldsymbol{V} \cdot \nabla T_{k}-w_{T} \frac{\partial}{\partial z} T_{k}+S_{T}(\boldsymbol{T})-R_{T}(\boldsymbol{T})$,

where $T_{k}$ is the concentration field of the $k$ th tracer; $\boldsymbol{T}$ is the vector field of all tracer concentrations, $D$ is the eddy diffusivity coefficient, $\boldsymbol{V}$ is the three-dimensional ocean current field, $w_{T}$ is a supplementary particle-driven vertical motion, and $S_{T}(\boldsymbol{T})$ and $R_{T}(\boldsymbol{T})$ are the local rates of production (source) and loss (removal) as functions of $\boldsymbol{T}$. The additional vertical term includes movement associated with sinking of particles, e.g., calcium carbonate or silicate hard parts from large phytoplankton (Armstrong et al., 2001), or alternatively buoyant rise associated with TEP (transparent exopolymeric particles; Azetsu-Scott and Passow, 2004).

The labile portion of DOC is removed instantaneously during CESM simulations because it is low in mass and computational emphasis is usually placed on carbon budgeting. By contrast, all semilabile carbon is treated as a single aggregate tracer with a 100-day lifetime (Moore et al., 2004).

\subsection{Mapping of macromolecules to marine biogeochemical variables}

The development of the macromolecule distributions begins from the premise that the major source of marine DOC is cell lysis, i.e., the disruption of cell exteriors resulting in the release of organic components to the water (Kujawinski et al., 2002). This can follow from viral attack, grazing by larger zooplankton, or senescence, i.e., aging. Phytoplankton exudate is a smaller, but still important source of DOC (Carlson, 2002).

We apportion DOC among five classes of organic compounds (with abbreviations in parentheses): (1) Proteins (Prot), (2) polysaccharides (Poly), (3) lipids (Lip), (4) humic acid and related compounds (Hum), and the remainder assigned to (5) geochemically aged and mixed compounds (Proc). We summarize these five classes of compounds in the carbon concentration vector field $\boldsymbol{C}$ :

$\boldsymbol{C}=($ Prot, Poly, Lip, Hum, Proc).

The model species we have chosen as chemical representatives of these classes are discussed in detail in Sect. 3.2 and also in parallel work focused on the marine surfactant chemistry 5.2 .

The analysis strategy is as follows: first, calculate the distributions of the freshly produced compounds offline based on POP/BEC results - proteins, polysaccharides and lipids derived from DOC. Second, calculate the distribution of the 
(a) Stearic acid and lysozyme

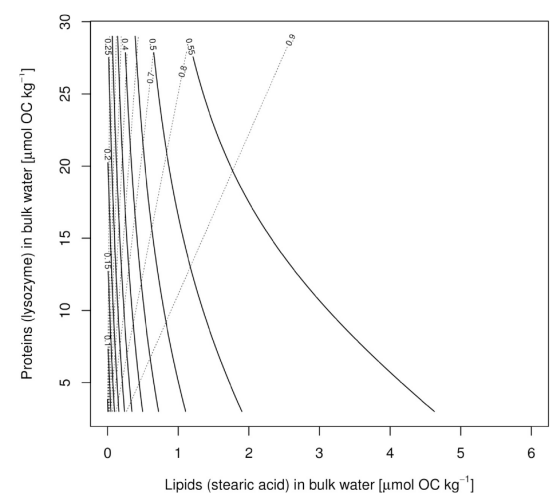

(b) Stearic acid and casein

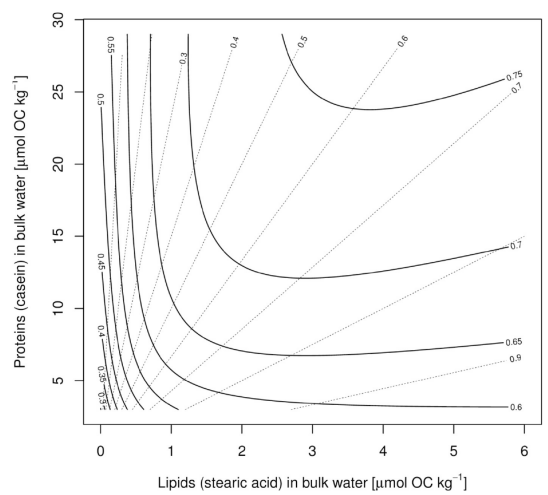

Figure 5. Organic mass fractionation in a two-component model including stearic acid and either lysozyme or casein (with properties as specified in Tables 1 and 2) and over a range of OC concentrations estimated from the ocean biogeochemical model as described in Sect. 5. Dark solid lines show total organic mass fraction of film aerosol. Thin dashed lines show the fraction of organic mass that is contributed by stearic acid.

remaining "processed" compounds. Third, calculate the additional humic compounds resulting from deep overturning in the winter at high latitudes.

Lipids are extremely short-lived (Parrish, 1988; Parrish et al., 1992), so we treat them as existing in a local steady state determined by rates of phytoplankton production and disruption with a lifetime of 10 days:

$C_{3}=S_{3} \cdot \tau_{3}$,

where $S_{3}$ is the production rate of lipids and $\tau_{3}=10$ days is the assumed lifetime of lipids in ocean surface water. The source term $S_{3}$ is assumed to be proportional to the product of the phytoplankton carbon concentration $C_{\text {phyto }}$ and the rate of phytoplankton disruption by zooplankton:

$S_{3}=0.2 \cdot k_{\text {disrupt }} \cdot C_{\text {phyto }} \cdot \frac{C_{\text {zoo }}}{\overline{C_{\text {zoo }}}}$,

where $C_{\text {zoo }}$ is the zooplankton carbon concentration with geographic mean value $\overline{C_{\text {zoo }}}$, and $k_{\text {disrupt }}$ is a pseudo-rate constant, set to a value of $1 / 300 \mathrm{day}^{-1}$. The factor 0.2 reflects the assignment of $20 \%$ of freshly produced DOC from phytoplankton spillage to the lipids.

The distribution of lipids (Fig. 6a) reflects the distribution of phytoplankton primary production (Eq. 10 ). $S_{3}$ is taken to be $20 \%$ of dissolved carbon flow computed from BEC. Our method of reconstructing the $C$ flux is similar to that introduced by Elliott (2009) for the simulation of organosulfur compounds in global DMS simulations.

Polysaccharides are the longest-lived among the freshly produced compound classes (Kaiser and Benner, 2009), and they are presumed here to be identical with the POP semilabile dissolved organic carbon (SDOC):

$C_{2}=\mathrm{SDOC}$
Proteins are of intermediate lifetime and are observed to contribute a fraction of the marine organic matter that lies between that of lipids and of polysaccharides (Tanoue, 1992; Hubberten et al., 1994; Kuznetsova et al., 2004; Kaiser and Benner, 2009). We thus estimate the protein concentration as one-third of the SDOC:

$C_{1}=\frac{1}{3} \cdot \mathrm{SDOC}$.

As shown in Fig. $6 \mathrm{~b}$ and c, polysaccharides and proteins are present in broad regions associated with higher marine biological activity.

We assign the remaining surface DOC to the class "processed carbon". Processed carbons and humic materials represent the recalcitrant portion of DOC, with lifetimes ranging from decades to tens of thousands of years (Hedges et al., 2001; Benner, 2002; Hansell et al., 2012). Annual average DOC was approximated as a function of latitude consistent with climatological data (Hansell et al., 2012), with fine structure and seasonality filtered then reinjected from the POP SDOC. The other surface macromolecules were then subtracted, leaving behind the mixed, processed polymers (Benner, 2002; Kaiser and Benner, 2009). We further apply a lower limit to the concentration of processed compounds in order to prevent unrealistically low or negative concentrations, $C_{5, \min }=3 \mu \mathrm{mol} \mathrm{C}^{-1}$. This processed carbon is then

$C_{5}=\max \left[\left(\mathrm{DOC}_{\mathrm{total}}-\sum_{i=3}^{3} C_{i}\right), C_{5, \min }\right]$.

The distribution of processed carbon is shown in Fig. 6d. Processed carbon constitutes the vast majority of the DOC, particularly in oligotrophic zones.

Humics include abyssal carbon carriers and are estimated based on the timing and depth of convective turnover. Convection is parameterized in POP by the KPP (K-profile 
(a) Lipid-like mixture

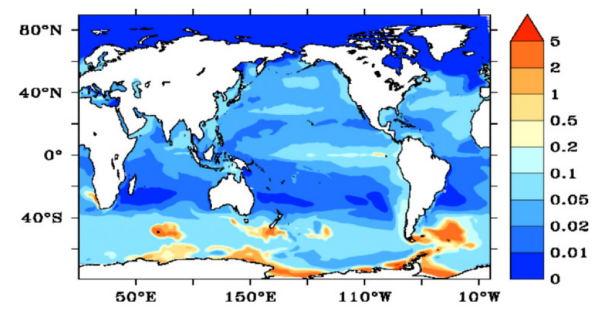

(c) Protein-like mixture

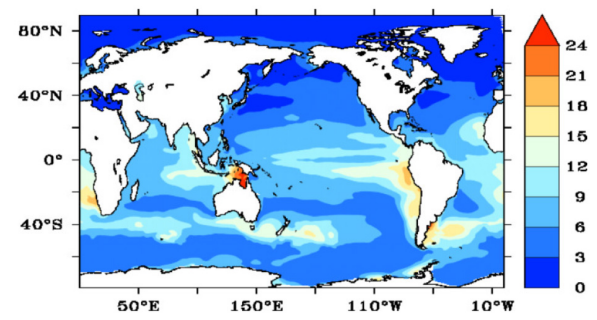

(b) Polysaccharide-like mixture

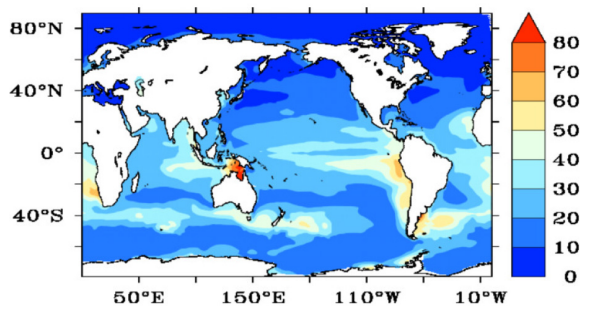

(d) Processed mixture

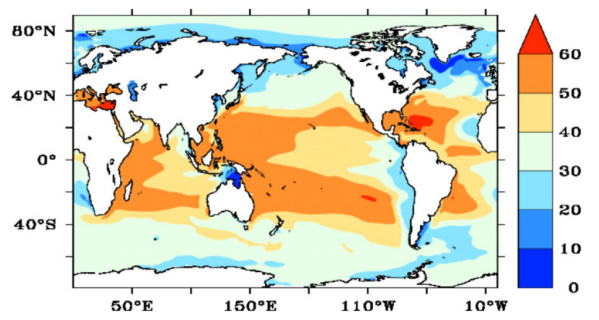

(e) Deep abyssal humic-like mixture

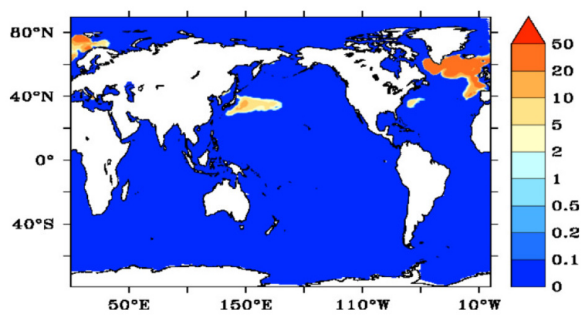

Figure 6. Ocean surface concentration of each compound class $\left(\mu \mathrm{mol} \mathrm{L}^{-1}\right)$ in February. Ocean concentrations for May, August and November are provided in the Supplement Figs. S1, S2, and S3.

parameterization) nonlocal vertical mixing scheme (Large et al., 1994), which predicts the eddy diffusivity $D$ as a function of water column stability and generates turnover below typical mixed-layer depths in high-latitude winter. For the purposes of this analysis, we assume that overturning occurs when the mixed-layer depth exceeds a threshold value. We further assume that prior to overturning, lipids, proteins, polysaccharides, and processed compounds are initially wellmixed from the surface to the mixed-layer depth $h_{\mathrm{ML}}$ (specified as $200 \mathrm{~m}$ ) and that humics are initially well-mixed in a layer extending from $h_{\mathrm{ML}}$ to the depth of convective mixing, $h_{\text {conv }}$. The mixed-layer concentration of the surface organic classes is the vector $C_{\mathrm{ML}}$ :

$C_{\mathrm{ML}}=\left\{C_{1}, C_{2}, C_{3}, 0, C_{5}\right\}$.

The pre-overturning concentration of deep humic substance below the mixed layer is set to $50 \mu \mathrm{MC}$, representative of a global average abyssal carbon concentration (Benner, 2002; Dittmar and Kattner, 2003; Hansell et al., 2012):

$C_{\text {deep }}=\{0,0,0,50,0\}$ where overturning is triggered, it is assumed to result in instantaneous, homogeneous mixing from the surface to $h_{\text {conv }}$. Concentrations after overturning are then

$\boldsymbol{C}=\boldsymbol{C}_{\mathrm{ML}}\left(h_{\mathrm{ML}} / h_{\mathrm{conv}}\right)+\boldsymbol{C}_{\mathrm{deep}}\left(\left(h_{\mathrm{conv}}-h_{\mathrm{ML}}\right) / h_{\mathrm{conv}}\right)$.

As shown in Fig. 6e, this has the effect of focusing humic activity in well-understood zones of deep turnover (Longhurst, 1998; Oliver and Irwin, 2008).

\subsection{Results: global geography of the Langmuir adsorption of macromolecules}

We apply selected surface activity and physical properties to predict the bubble surface coverage and thereby the film organic mass fraction (Tables 1,$2 ; 5.3$ ). Results are shown in Fig. 7. Predicted organic mass fractions are between 10 and $20 \%$ in most regions, and exceed $50 \%$ in regions of high biological productivity. Mass enrichment factors are in the range 1000-2000 over much of the globe. Because the $\mathrm{OM}$ : Na ratio is more strongly conserved than the $\mathrm{OM}: \mathrm{NaCl}$ ratio (due to chlorine depletion in the atmosphere), it is also 

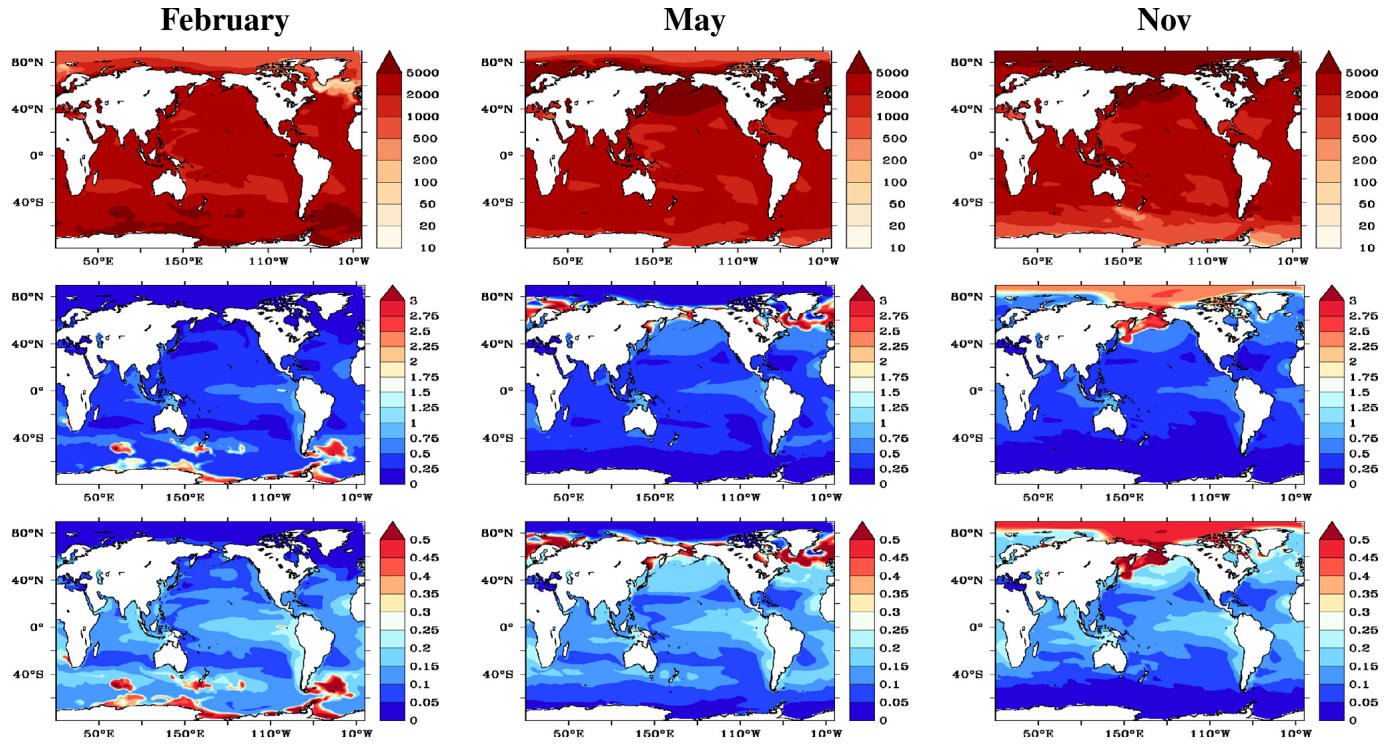

Figure 7. Global estimates of effective enrichment and organic mass fractions. Case BASE: using model compounds as described in Table 1. Top: effective mass enrichment ratio. Middle: OM : Na mass ratio in nascent film drop aerosol. Bottom: organic mass fraction in nascent film drop aerosol. Left: February. Center: May. Right: August.

presented in the middle panels; values range from less than 1 over most of the globe to more than 2.5 in phytoplankton blooms. For comparison, typical OM : Na mass ratios measured during the ICEALOT (International Chemistry Experiment in the Arctic LOwer Troposphere) campaign in the Arctic and North Atlantic in March were approximately $0.7-0.8$ (Russell et al., 2010). Predicted organic mass fractions of the nascent film drops are shown in the lower panels, and range up to about 0.5. In tropical upwelling zones, e.g., in the equatorial Pacific, the model predicts very similar organic enrichment in February and in August, reflecting the limited seasonality of nutrient and light availability near the Equator. The highest organic enrichments are predicted in the locations with active seasonal blooms, e.g., the Labrador Sea in August and the Antarctic Sea in February. Spring blooms are not shown in the interest of space but are also represented, e.g., the North Atlantic bloom reaches a peak around May.

Figure 8 shows the mass fractions of the dry submicron SSA that are contributed by of each the four organic compound classes: polysaccharides, proteins, lipids, and humics (processed compounds are not shown because their contribution is negligible). Although lipids contribute very little of the ocean DOC (Fig. 6a), they contribute the majority of the aerosol OC in regions of high productivity (Fig. 8c). In lessproductive waters, organic mass is primarily contributed by proteins, and polysaccharides are also a significant contributor (Fig. 8b, a).

\subsection{Chl $a$ : OM relationship and comparison with previous parameterizations}

In the presentation of some of the remaining results, we have chosen to highlight several geographic regions that are of interest as locations for field campaigns, or to highlight differences between ocean ecosystems. These regions are defined in Fig. 9. To compare our model with existing chl $a$-based parameterizations, we show the predicted relationship between chlorophyll concentration as predicted by the POP and the sea spray organic mass fraction in February, May, August and November, visually highlighting points from each of the selected geographic regions (Fig. 10). The functional shape of the chl $a-\mathrm{OM}$ fraction relationship resembles empirical relationships derived by other authors and largely falls within observational constraints (Gantt et al., 2011; Long et al., 2011). Organic mass fractions increase rapidly at lower chlorophyll concentrations, and then begin to flatten out at higher chlorophyll concentrations, as surfaces approach saturation. However, the predicted chl $a-\mathrm{OM}$ relationship varies depending on region and season. For example, in May, for the same values of chl $a$, predicted OM fractions are significantly higher in the North Atlantic than in the Arctic, consistent with observations (Russell et al., 2010).

\subsection{Seasonal cycles in chl $a$ and OM}

Although global mean concentrations are relatively constant throughout the year (Table 3), certain regions have a strong seasonal cycle in average OM fraction. For the geographic regions defined in Fig. 9, the regionally averaged seasonal cycles of total OM fraction, lipid fraction, the total of protein 
(a) Polysaccharides

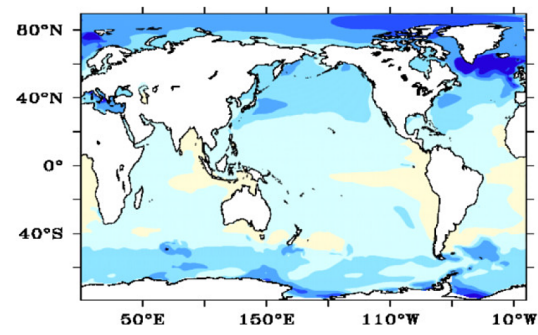

(b) Proteins
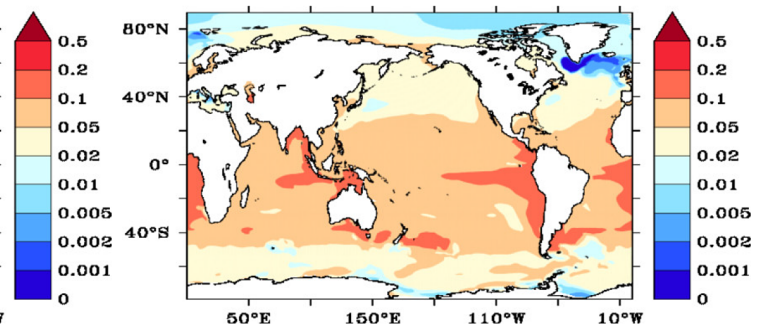

\section{(c) Lipids}

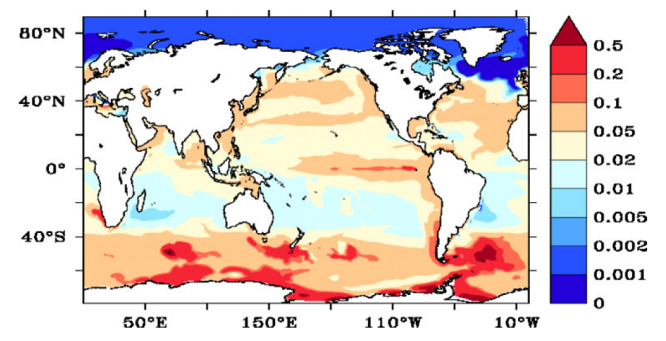

Figure 8. Submicron SSA dry mass fraction from each compound class for February (BASE case). Fractions of processed and humic classes (not shown) are negligible.

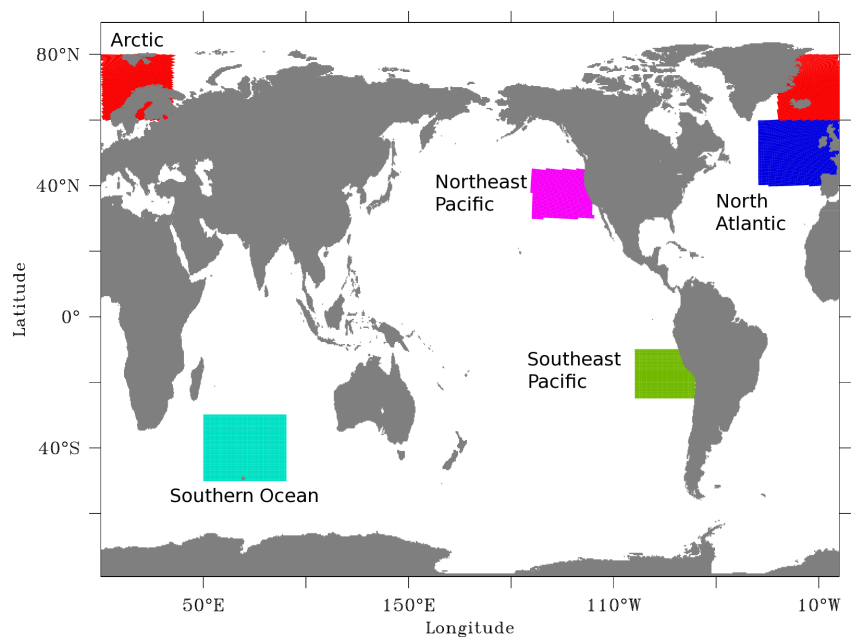

Figure 9. Geographic regions as defined in this paper.

and polysaccharide fraction, and chl $a$ are shown in Fig. 11, and the regional mean values of $\mathrm{OM}$ fraction are compared in Table 3. Regions characterized by strong seasonal blooms such as the Arctic, North Atlantic and Southern Ocean display strong seasonal cycles in the total OM fraction, while in the Northeast Pacific and Southeast Pacific, the seasonal cycle is far more muted. The relative contributions of the lipids and the semilabile classes (proteins and polysaccharides) also vary seasonally and between regions. In the North
Table 3. Regional seasonal mean mass fractions for each region as defined in Fig. 9.

\begin{tabular}{|c|c|c|c|c|}
\hline & Feb & May & Aug & Nov \\
\hline \multicolumn{5}{|c|}{ BASE case - regional mean values } \\
\hline North Atlantic & 0.04 & 0.31 & 0.19 & 0.12 \\
\hline Arctic & 0.02 & 0.36 & 0.19 & 0.07 \\
\hline Northeast Pacific & 0.10 & 0.14 & 0.12 & 0.12 \\
\hline Southeast Pacific & 0.18 & 0.17 & 0.15 & 0.17 \\
\hline Southern Ocean & 0.20 & 0.13 & 0.08 & 0.15 \\
\hline GLOBAL & 0.14 & 0.14 & 0.14 & 0.13 \\
\hline \multicolumn{5}{|c|}{ Global mean values - sensitivity cases } \\
\hline Global $-l_{\text {bub }}=0.5$ & 0.03 & 0.04 & 0.04 & 0.03 \\
\hline Global - LOW-LIP & 0.09 & 0.09 & 0.09 & 0.09 \\
\hline Global - HIGH-PROT & 0.33 & 0.33 & 0.32 & 0.33 \\
\hline Global - HIGH-HUM & 0.16 & 0.15 & 0.15 & 0.14 \\
\hline
\end{tabular}

Pacific, the total OM fraction remains relatively constant, but the relative contributions of lipids versus proteins and polysaccharides vary over the course of the year.

To better understand the seasonality of the chl $a-\mathrm{OM}$ relationship, we calculated the correlation between monthly mean POP-simulated chl $a$ and monthly mean aerosol organic fraction (Fig. 12). Areas with strong seasonal blooms, such as the North Atlantic, exhibit strong positive correla- 
(a) February

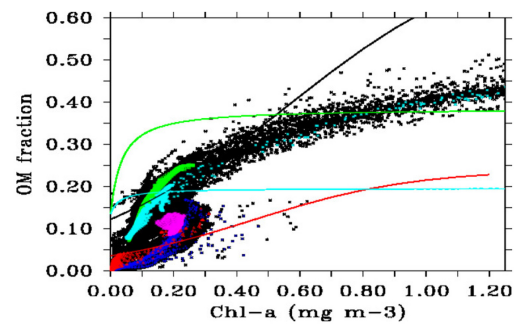

(b) May

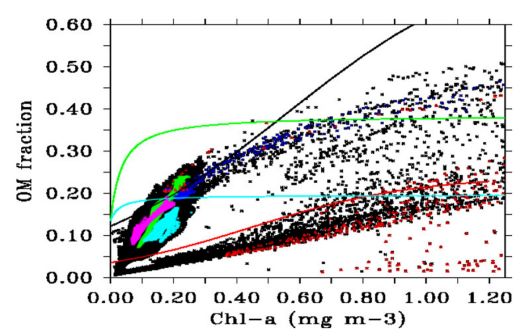

(c) August

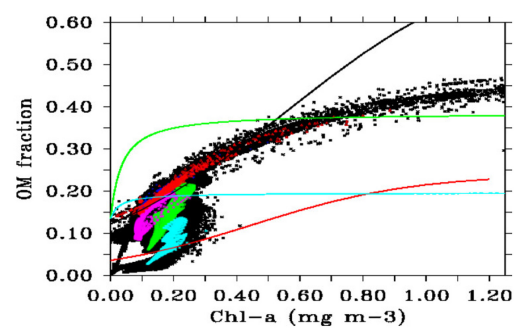

(d) November

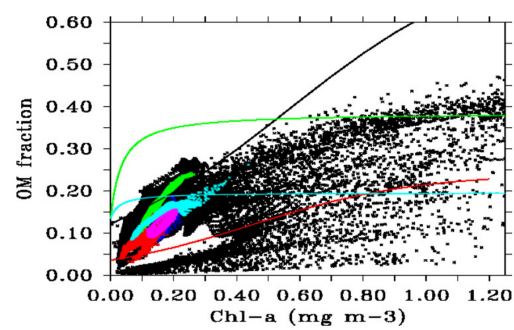

Figure 10. POP-simulated chl $a$ vs. submicron SSA dry organic mass fraction, with model output from five geographic regions highlighted (BASE case). Colored points are data in the regions shaded in corresponding colors in Fig. 9, i.e., red: Arctic; dark blue: North Atlantic; magenta: Northeast Pacific; green: Southeast Pacific; cyan: Southern Ocean. Black points indicate rest of world. Black and red lines indicate empirical fits to observations from Mace Head, Ireland $\left(D_{\mathrm{p}}<1.5 \mu \mathrm{m}\right)$, and Point Reyes, California $\left(D_{\mathrm{p}}<2.5 \mu \mathrm{m}\right)$, respectively (Gantt et al., 2011). Blue and green lines show the parameterization of Long et al. (2011) for particle diameters of 0.8 and $0.5 \mu \mathrm{m}$, respectively.

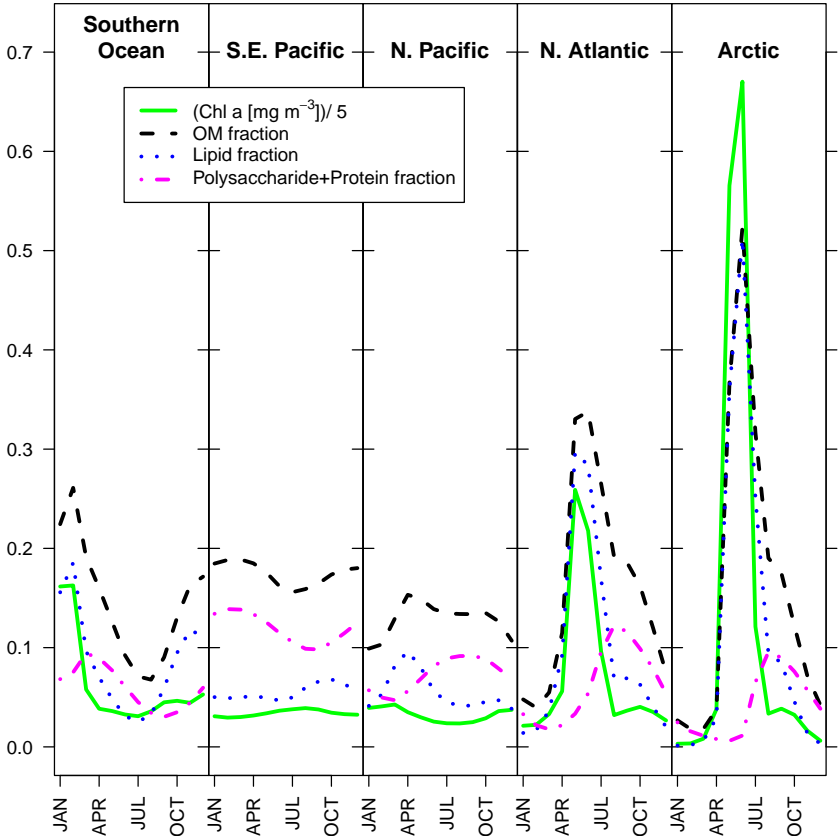

Figure 11. Monthly mean values from the BASE case for ocean regions indicated in Fig. 9. Green solid line: POP-simulated chl $a$ $\left(\mathrm{mg} \mathrm{m}^{-3}\right) / 5-$ Note that $\mathrm{chl} a$ is scaled to improve legibility of seasonal trends. Black dashed line: total submicron SSA dry organic mass fraction. Blue dotted line: lipid mass fraction. Magenta dotdash line: polysaccharide + protein mass fraction.

tions (compare Figs. 6a and 8c for locations of simulated blooms in Southern Hemisphere summer; seasonal cycle is shown in Fig. 11). In regions such as the Southeast Pacific, spring blooms are weaker, and semilabile DOM accumulates over the course of the spring and summer seasons, approaching its peak as chl $a$ declines (Fig. 11). In these regions, monthly mean chl $a$ and SDOC can be anticorrelated, and SDOC contributes significantly to estimated aerosol organic mass (polysaccharides and proteins). This produces the anticorrelation between the chl $a$ and OM fraction evident in our model in some regions.

Because the values of the model parameters are highly uncertain, we explore some of the uncertainties in a small set of sensitivity tests. Some of the figures referenced in this section are available in the online supplementary material. This is indicated by the figure number having the prefix " $S$ ". Summary results are presented in Table 3 .

\subsubsection{Low lipid adsorptivity}

First, because lipids drive much of the variability in predicted OM enrichment, we show a case in which the lipid adsorptivity $\alpha_{\text {lip }}$ has been reduced by a factor of 10 (LOWLIP; Fig. S4; middle row). In this scenario, the maximum $\mathrm{OM}$ fraction in bloom regions is ca. 0.3, compared to $>0.5$ in the BASE case. By contrast, in the midlatitude oceans, 
(a) BASE case

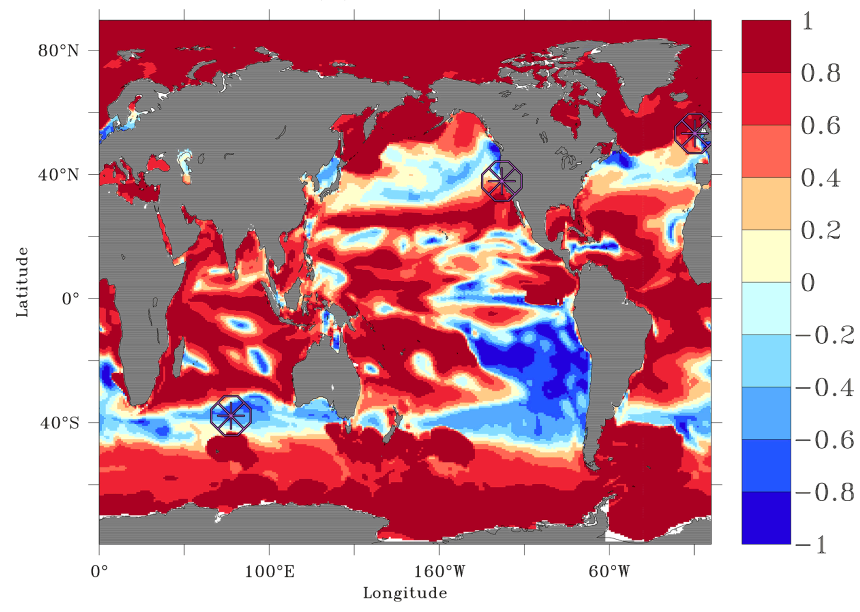

(b) LOW-LIP case

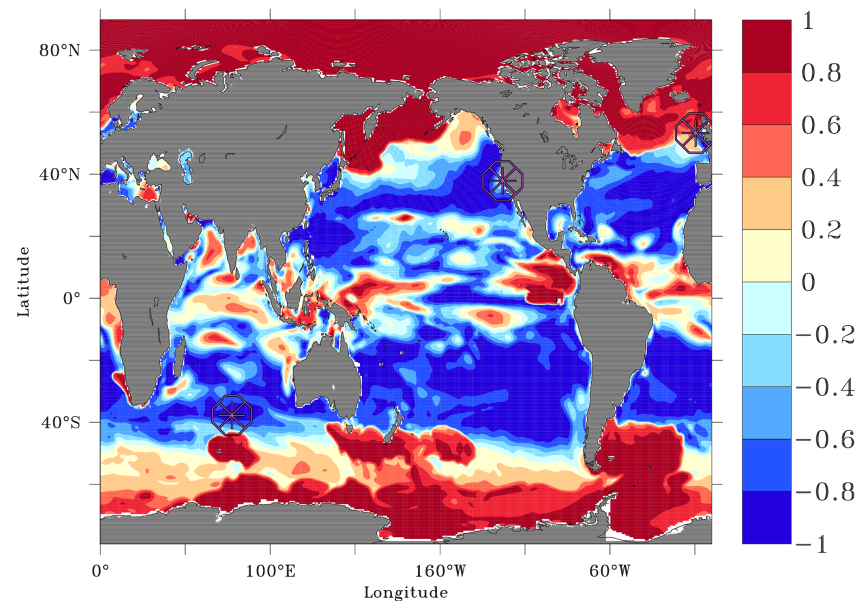

Figure 12. Correlation between POP-simulated monthly mean chl $a$ and predicted monthly mean organic mass fraction for 1 simulated year, for the BASE case and LOW-LIP case. Stars indicate the locations of Mace Head, Ireland; Point Reyes, California; and Amsterdam Island (Southern Ocean).

e.g., in the southeastern Pacific, the OM fraction is dominated by the SDOC-associated polysaccharides and proteins and changes little between the BASE and LOW-LIP cases. Because the influence of lipids on the aerosol OM is reduced in the LOW-LIP case, the SDOC-dominated regions with a negative correlation of chl $a$ and aerosol OM fraction expand for this case (Fig. 12b).

\subsubsection{Sensitivity to assumed bubble film thickness}

The bubble film thickness is another important uncertain parameter. Changing the bubble film thickness from 0.1 to $0.5 \mu \mathrm{m}$ results in a significant decrease in the organic mass fraction ("FILM-0.5"; Fig. S4; bottom row). Film thickness can be as small as ca. $0.01 \mu \mathrm{m}$ for bubbles with high concentrations of soluble surfactants, and as large as ca. $1 \mu \mathrm{m}$ for bubbles in clean water (Modini et al., 2013). In additional tests (not shown), we varied the film thickness across this range as a function of bubble surface coverage. Because we used $l_{\text {bub }}=0.1 \mu \mathrm{m}$ when bubble surface coverage exceeded a threshold value, the organic enrichment remained the same in the regions with the highest enrichment, but decreased somewhat in regions of lower enrichment.

\subsubsection{Test assuming uniform adsorptivity of DOC}

In a third sensitivity test ("EXUDATE"; Fig. S5; top row), we applied the same properties to all four compounds: the average properties of filtered exudate from four phytoplankton species, measured by Fuentes et al. (2011), with OM : OC ratios from the mean stoichiometry of phytoplankton biomass (Fraga, 2001). The surface activity of the filtered exudate is insufficient to generate substantial enrichment of the bubble film (Fig. S5). Furthermore, by treating all DOM as chemically identical, it is impossible to produce patterns of the $\operatorname{chl} a$ : OM fraction ratio resembling observations from strong seasonal blooms (Fig. S5; top row).

We conclude that these filtered exudates cannot be considered representative for marine organic material in general and in particular for enrichment associated with a phytoplankton bloom. One possible explanation is that the surface activity of the marine phytoplankton exudate may have been significantly reduced by filtration (Ẑutić et al., 1981). Furthermore, marine ecosystem processes (e.g., attack of phytoplankton by zooplankton and recycling of organic matter by heterotrophic bacteria) and photochemistry may modify the surface activity of DOM.

\subsubsection{Tests with high adsorptivity of proteins and humics}

Results from two additional tests are shown in Fig. S5 (top row). In one test ("HIGH-PROT"; Fig. S5; middle row), we use casein, rather than lysozyme, as the model protein; i.e., we increase the value of $\alpha_{\text {prot }}$ by a factor of 10 . This results in organic mass fractions exceeding 0.2 and enrichment factors exceeding 5000 over most of the globe. In a final test ("HIGH-HUM"; Fig. S5; bottom row), we increase $\alpha_{\text {humic }}$ by a factor of $10^{4}$, which produces increased enrichment in confined regions of strong seasonal upwelling.

\subsubsection{Summary of sensitivity cases}

We summarize the global organic mass fractions predicted for different sensitivity cases in Table 3 . In all the sensitivity cases, the global mean is very constant across the seasons.

Comparing the sensitivity cases, it can be seen that the overall OM fraction exhibits the largest relative change with the factor of 5 increase in the bubble film thickness, decreasing by nearly a factor of 5 in response. A decrease in the lipid adsorptivity by a factor of 10 results in only a ca. $35 \%$ decline in the global mean OM fraction relative to the BASE 
case. An increase in the protein adsorptivity by a factor of 10 results in an approximate doubling of the global mean OM fraction. This is consistent with recent findings that the total marine OM emissions simulated by global model parameterizations are more sensitive to the emissions in oligotrophic regions than to the emissions in strong blooms (Albert et al., 2012). Finally, a large perturbation $\left(\times 10^{4}\right)$ to the adsorptivity of the abyssal humic-like compounds results in only a small change in the global mean OM fraction, because changes are confined to small regions of winter convective overturning (Fig. S5; bottom row).

\subsection{Comparison with field observations}

Although we have introduced a parameterization for the $\mathrm{OM}$ fraction, simulations of atmospheric transport, microphysics, and chemical transformations in the atmosphere are beyond the scope of this work. Here we present a brief initial comparison of the parameterized OM fraction and functional group ratios with observations from field campaigns and coastal sites. While these comparisons give initial insights into the performance of the emissions parameterization, it should be noted that there are important limitations. Because we have not yet treated atmospheric transport or simulated interannual variations in this initial development work, at this stage we compare observations only with monthly mean predictions of the composition of emitted aerosol, averaged over a region including the field campaign location, or over a region upwind of coastal locations where samples were collected. Unless otherwise stated, all comparisons are with the BASE simulation. Simulations that include effects of atmospheric transport, microphysics, and chemical aging, as well as detailed comparisons with in situ observations, are the planned topics of a future publication.

\subsubsection{Comparison of total OM fraction with shipboard and coastal observations}

We first compare the total OM fraction with shipboard and coastal observations. The observations presented include the water-insoluble OM fraction (WIOM) observed at coastal stations (Gantt et al., 2011; Rinaldi et al., 2013) and observations of OM fraction in ambient aerosol from ship campaigns (Russell et al., 2010, 2013), and in aerosol generated in situ by bubbling air through seawater during ship campaigns (Quinn et al., 2014). All observations of ambient aerosol have been screened for marine conditions with little anthropogenic pollution, but each investigator has used different criteria for screening. For the coastal observations, paired values of upwind chl $a$ have been used, consistent with previous studies (Gantt et al., 2011; Rinaldi et al., 2013).

The top panels of Fig. 13 compare the model predictions of the seasonal cycle with observations. Each comparison is shown for three geographic regions: coastal California (left), the North Atlantic bloom region upwind of Mace Head (mid- dle), and the coastal region of the northwestern North Atlantic (right). Because each ambient aerosol measurement may have been influenced by emissions from a large region upwind of the measurement location, for the purposes of this comparison, we have averaged the model OM fraction over larger regions as indicated in Fig. 9, or as otherwise indicated.

The model is in reasonably good agreement with the seasonal cycle at Mace Head, falling within the range of observations for most months. The underestimation of the $\mathrm{OM}$ fraction in March, April, and August may be caused by the winter overturning, which may be removing surfactants too effectively in the model (Sect. 5). At Point Reyes, the few available observations indicate a relatively constant seasonal cycle without a strong peak, behavior which is qualitatively reproduced by the model.

The bottom panels of Fig. 13 show the chl $a$ vs. OM fraction relationships in the same three regions, for chl $a$ values in the range of $0-1.25 \mathrm{mg} \mathrm{m}^{-3}$. Note that the model values presented here represent the regionally averaged chl $a$ and OM fraction and as such, do not reflect the full range of variability of the model, shown in Fig. 10. Observations indicate a much stronger dependence of OM fraction on chl $a$ in the North Atlantic/Arctic region influencing Mace Head, Ireland, than in the Pacific region influencing Point Reyes; however, this is at least in part due to the different particle size fractions observed at those two stations. The model's regionally averaged monthly mean values do not approach the highest OM fractions observed at Mace Head, but are mostly within the range of the observations for chl $a<1$ in both regions. In the coastal northwestern Atlantic, the WACS generated aerosol is within the range of low-chl $a$ observations.

In Fig. 14, we compare regionally averaged monthly mean OM fractions from our emissions parameterization with climatological monthly means of observed WIOM from the same two sites. The comparatively lower WIOM fractions at Point Reyes compared to Mace Head are at least partially attributable to the different size fractions measured at the two sites (sub-1.5 $\mu \mathrm{m}$ at Mace Head and sub-2.5 $\mu \mathrm{m}$ at Point Reyes). Since we have not corrected here for the particle size fraction observed, it is not surprising that our model underpredicts the Point Reyes observations while simultaneously overpredicting the Mace Head observations.

\subsubsection{Comparison of estimated functional group composition with FTIR measurements}

In this section, we compare the model estimates with mean values from FTIR (Fourier transform infrared) measurements of submicron SSA collected during several ship-based field campaigns in Fig. 15. For the purpose of this comparison, the macromolecular classes have been converted to functional group-associated mass using the weights presented in Table 4 . Higher alkane : hydroxyl ratios indicate an aerosol that is more lipid-like and dominated by long aliphatic chains. 

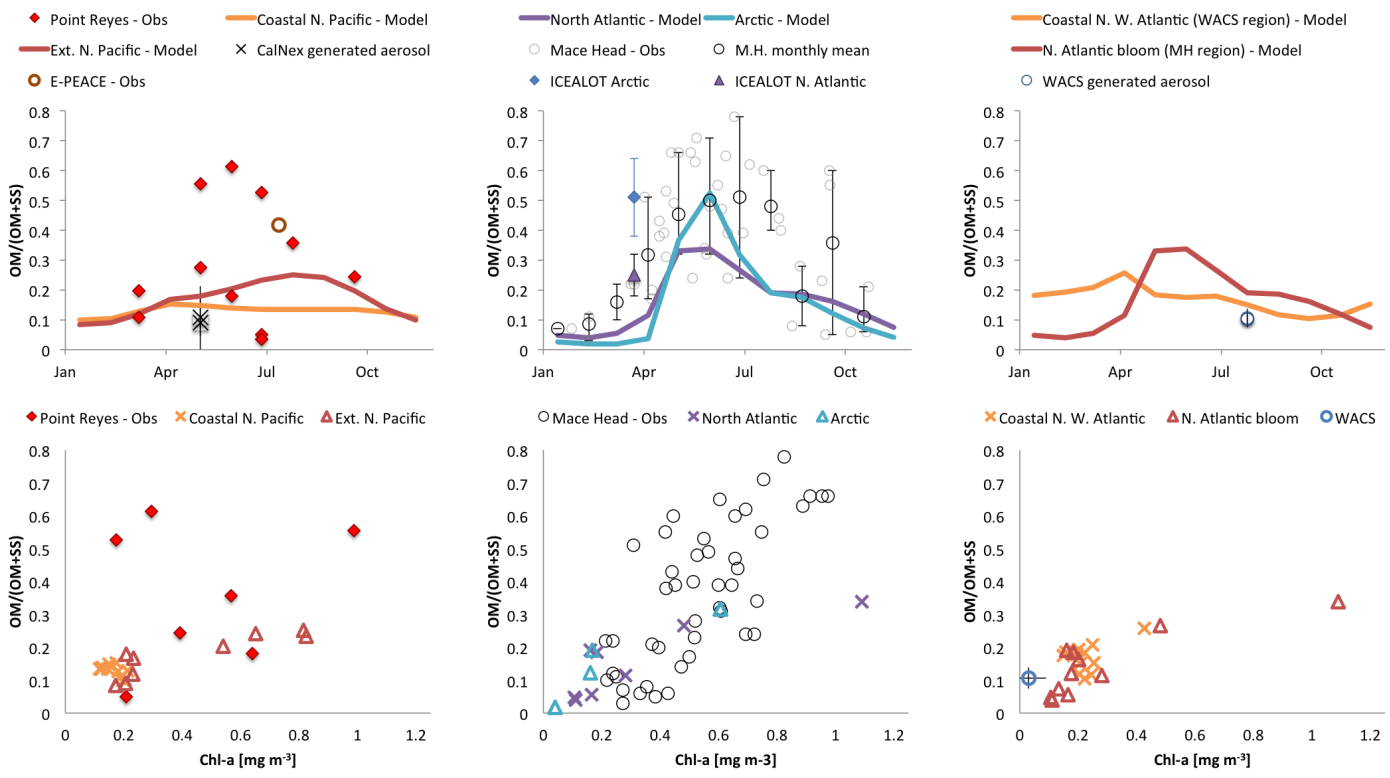

Figure 13. Observed OM or WIOM fraction and modeled OM fraction in three regions. Left: coastal California and North Pacific, compared with Point Reyes and E-PEACE campaign. Middle: North Atlantic bloom region and Arctic, compared with Mace Head and ICEALOT campaign. Right: northwest North Atlantic, compared with the WACS campaign. Top: seasonal cycle. Bottom: relationship with observed or modeled chl $a$. Point Reyes observations $(\mathrm{N}=10)$ are compared with model OM fraction averaged over a coastal North Pacific region (Fig. 9) and an extended region covering most of the North Pacific (20-40 N, 120-210 W). Mace Head observations ( $\mathrm{N}=42)$ are compared with model composition averaged over the North Atlantic and Arctic regions (Fig. 9). Error bars for WACS and CalNex are $95 \%$ confidence intervals (by a $t$ test); error bars for VOCALS and ICEALOT are 1 standard deviation; error bars for monthly mean Mace Head observations are the range of observed values in the calendar month.

Table 4. Conversion from moles of carbon per macromolecule class to the mass associated with FTIR-observable functional groups, ((grams of the functional group) / (moles of carbon per macromolecule) $)^{\mathrm{a}}$.

\begin{tabular}{lcccc}
\hline & Alkane & Hydroxyl & Carboxyl & Amine \\
\hline Lipids $^{\mathrm{b}}$ & 10.11 & 0.85 & 0 & 0 \\
Polysaccharides $^{\mathrm{c}}$ & 7.0 & 19.17 & 0 & 0 \\
Proteins $^{\mathrm{d}}$ & 6.18 & 1.35 & 18.53 & 6.47 \\
Processed $^{\mathrm{e}}$ & 7.0 & 19.17 & 0 & 0 \\
Humics & 7.0 & 19.17 & 0 & 0 \\
\hline
\end{tabular}

a Molar mass associated with a functional group is assumed to include half the mass of the carbon atom if single-bonded and the full mass of the carbon atom if

double-bounded, e.g., $\mathrm{C}-\mathrm{H}$ mass is $7 \mathrm{~g} \mathrm{~mol}^{-1}$ (including half the mass of the carbon atom), and $\mathrm{COOH}$ mass is $45 \mathrm{~g} \mathrm{~mol}^{-1}$ (including the full mass of the carbon atom). Functional group distribution per macromolecule class ((moles functional group) / (moles carbon)) is estimated based on model compounds as indicated.

$\mathrm{b}$ Functional group mass distribution of cholesterol.

${ }^{c}$ Functional group mass distribution characteristic of simple sugars.

${ }^{\mathrm{d}}$ Characteristic functional group mass distribution of a mixture of amino acids present in seawater.

e Same as for polysaccharides.

Lower alkane: hydroxyl ratios indicate an aerosol that is more oxidized and carbohydrate-like.

The lowest observed alkane:hydroxyl ratios are from clean marine samples collected during E-PEACE (Eastern Pacific Emitted Aerosol Cloud Experiment; alkane : hydroxyl $=0.24)$, off the central coast of California, in the presence of high chlorophyll. These are followed by samples from the ICEALOT campaign, which transected the North Atlantic bloom (alkane: hydroxyl=0.38) and the polluted marine samples from the Arctic Sea (alkane : hydroxyl $=0.60$ ). Alkane: hydroxyl ratios were higher in polluted marine air during the VOCALS-Rex campaign (VAMOS Ocean-Cloud-Atmosphere-Land Study Regional Experiment; alkane : hydroxyl $=2.00$ ), located in the Southeast Pacific. In all cases, the average alkane : hydroxyl ratio is lower in the clean-air samples than in polluted samples, suggesting that anthropogenic pollutants are associated with a higher proportion of long aliphatic chains and perhaps a lower oxidation state relative to primary marine organic aerosol emissions. The alkane:hydroxyl ratio may also be affected by ocean biological processes: the model suggests it will be highest during strong seasonal blooms (Fig. S6).

We compare the observations with the mean and range of estimated alkane-to-hydroxyl ratios from the model's BASE case and two sensitivity cases: LOW-LIP (10 times lower lipid adsorptivity) and LOW-LIP+HIGH-POLY (10 times lower lipid adsorptivity and 20 times higher polysaccharide adsorptivity). Results from clean marine conditions are in better agreement with the LOW-LIP+HIGH-POLY case. 


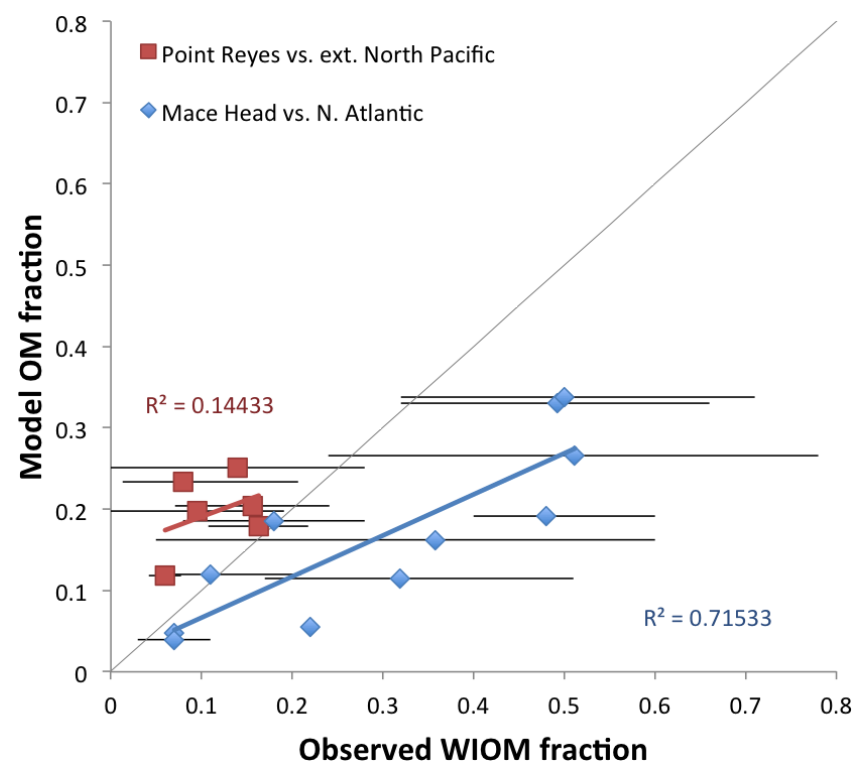

Figure 14. Observed monthly mean WIOM / (WIOM + SS) vs. modeled monthly mean OM SSA fraction, averaged over a region upwind of the respective measurement location. Observations shown are: (1) sub-1.5 $\mu \mathrm{m}$ WIOM fraction from a coastal site at Mace Head, Ireland ( $=42$ filters collected during the years 20022009), filtered for clean marine conditions (as described in Rinaldi et al., 2013) and (2) sub-2.5 $\mu \mathrm{m}$ WIOM fraction from a buoy located near Point Reyes, California ( $\mathrm{N}=10$ filters collected during the years 2000-2007), during clean conditions as determined by low BC concentrations (as in Gantt et al., 2011). Observations have been grouped into month-of-year means for appropriate comparison with model results. Error bars show the range of observations for each month. Model OM fractions are calculated over the North Atlantic region (as indicated in Fig. 9) and extended North Pacific region, respectively. Linear regressions and their corresponding $R^{2}$ values are shown for each data set. The 1:1 line is indicated in gray.

\subsubsection{Comparison with Quinn et al. (2014)}

Quinn et al. (2014) (hereafter Q14) present measurements of the organic carbon fraction of sea spray aerosol from the WACS field campaign in the northwestern North Atlantic and Sargasso Sea region (August, 2012). The organic enrichments observed by Q14 are in the same range as the OM predicted by our model in the same region in August, which range from about 0.05 in the Sargasso Sea to about 0.2 near the coast (Figs. 8,13). While our model predicts that the organic mass fraction is somewhat higher in regions with higher chlorophyll, Q14 shows similar average OM fractions at both a high-chl $a$ location and a low-chl $a$ location. However, the number of data points in the Q14 samples is too small to draw firm conclusions ( $\mathrm{N}=9$ and $\mathrm{N}=7$ at the highchl $a$ and low-chl $a$ station, respectively). Furthermore, the mean enrichment factors during WACS were higher for lowchl $a$ samples than for high-chl $a$ samples, and this difference was statistically significant $(p<0.001$ by a $t$ test calcu- lated from Table S1 of Q14 in the Supplement), which is consistent with the understanding that organic enrichment tends to be higher in biologically active waters. Q14 also includes results from the CalNex campaign (coastal California, May 2010), which are consistent within uncertainty bounds with the model (Fig. 13).

\subsubsection{Comparison with Keene et al. (2007)}

Keene et al. (2007) (hereafter K07) measured the chemical composition of aerosol generated, using a glass frit system, from low-chlorophyll water (chl $a=0.055$ ) from the Sargasso Sea. The aerosol produced in that had a median enrichment factor for soluble OC of 387 , and the OC fraction for the smallest particles produced $(0.13 \mu \mathrm{m})$ was ca. $80 \%$. Using the "medium" values of size-resolved aerosol composition reported in $\mathrm{K} 07$, we calculate an $\mathrm{OC} /(\mathrm{OC}+$ inorganics $)$ mass fraction of 0.26 for $0.75 \mu \mathrm{m}$ particles, and 0.076 for $1.34 \mu \mathrm{m}$ particles. Figure 10 shows that in grid points with chl $a=0.055$, our model predicts submicron OM fractions ranging up to a maximum of about 0.15 (OC fraction $=0.24$, assuming $\mathrm{OM}$ : $\mathrm{OC}=1.8$ ). This value is in reasonable agreement with the $\mathrm{K} 07$ results.

\section{Discussion}

This framework represents an initial step towards representation of the effects of ocean surface organic matter composition on sea spray aerosol composition. Many studies have identified a link between surface-active DOM concentrations and ocean biological activity, which sometimes manifests as a correlation between ocean concentrations of surfactants and chl $a$. For example, field studies in the northern Adriatic have found significant positive correlations between bulk surfactant activity in the SML and independent measurements, at the same stations, of chl $a$ concentration, phytoplankton primary production, $\mathrm{pH}$ and oxygen saturation (Ẑutić et al., 1981). These studies have also identified a seasonal cycle in surfactant concentrations, with the highest concentrations appearing in spring and summer (Gašparović and Ćosović, 2001). In phytoplankton cultures, surfactant activity has been found to increase in proportion to biomass, until leveling out at high surfactant concentrations, and observational studies have concluded that the largest source of surfactants in the SML is phytoplankton exudates and their degradation products (Ẑutić et al., 1981; Gašparović et al., 1998; Sekelsky and Shreve, 1999). Similarly, in an iron fertilization experiment in the Southern Ocean, concentrations of surface-active substances increased strongly during the bloom, reaching their highest concentrations at the end of the bloom (Croot et al., 2007). An important source of surfactants is the lysis of phytoplankton and spillage of their constituents into the water. This may explain results of a recent field study off the coast of California, in which the organic mass in spray aerosol gen- 


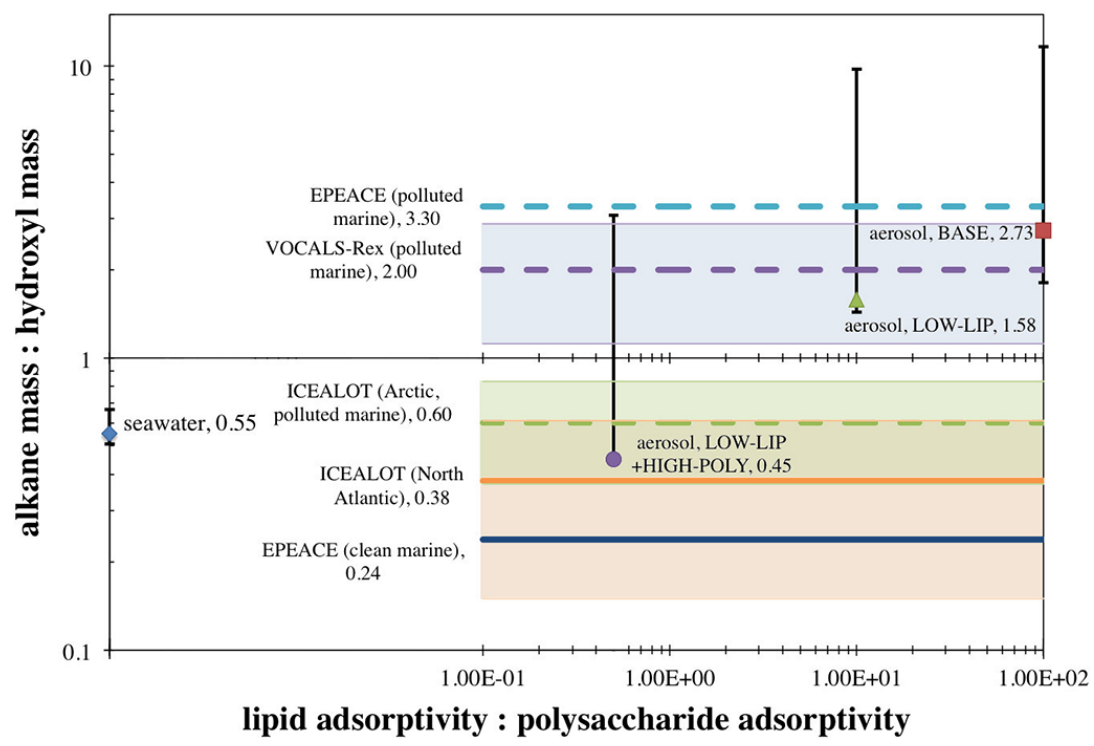

Figure 15. Ratio of alkane mass to hydroxyl mass from model macromolecules, and from shipborne FTIR observations. Points and error bars indicate the model's global median and 5-95th percentile range of model estimates for seawater (displayed at the left of the figure) and for emitted submicron SSA in several sensitivity cases. Medians and ranges are calculated from monthly mean grid-box values. For the purpose of this comparison, model macromolecule concentrations were converted to estimated functional group ratios using the values provided in Table 4. Model values are shown as a function of the ratio of the adsorption constants used for lipids and for polysaccharides, in each sensitivity case. Observed alkane : hydroxyl ratios from shipborne FTIR measurements in several field campaigns are shown as lines and shaded regions. The adsorptivity of the ocean DOC components during each campaign is unknown; therefore, the observed alkane : hydroxyl ratio is not associated with particular values on the $x$ axis. Solid lines indicate averages of data from clean air samples only, i.e., data from air contaminated by anthropogenic pollution have been excluded. The shipborne observations are from the E-PEACE campaign off the central coast of California (July-August, 2011) (Russell et al., 2013), the ICEALOT campaign in the North Atlantic and Arctic oceans (MarchApril, 2008) (Russell et al., 2010), and the VOCALS-Rex campaign, in the Southeast Pacific oligotrophic gyre (October, 2008) (Hawkins et al., 2010). The shaded areas indicate the \pm 1 standard deviation uncertainty range for VOCALS-Rex, ICEALOT (Arctic) and ICEALOT (North Atlantic), respectively.

erated with an in situ particle generator did not correlate with chlorophyll, but did correlate with the concentration of DMS in the ocean, indicating a possible relationship with cell lysis (Bates et al., 2012).

All of these observations support the interpretation that the correlation of the organic fraction of the spray aerosol with chl $a$ that is sometimes observed is driven by underlying ocean chemistry: specifically, by the high concentrations of strong surfactants in productive waters. More productive waters also have a greater proportion of larger particles (Buonassissi and Dierssen, 2010), which can further enhance the organic mass in the SSA. The parameterization proposed here is the first to explicitly link the physical surface chemistry of ocean bubbles and organic enrichment of the SSA.

\subsection{Sources of uncertainty and priorities for future experiments}

In this section, we discuss some of the main sources of uncertainty, currently neglected processes, and inherent limitations of our approach.

\subsection{Equilibrium assumption}

It is unclear how rapidly adsorption equilibrium is reached on bubble surfaces in the ocean. Estimates differ widely; for example, Fuentes et al. (2011) estimated an equilibration timescale of less than $0.05 \mathrm{~ms}$ for bubbles in a sample of filtered algal exudate, while Krzan et al. (2007) measured adsorption of several organic surfactants on single rising bubbles and observed equilibration to occur in less than $1 \mathrm{~s}$ in most cases. The rise velocities in seawater of bubbles with radii greater than $700 \mu \mathrm{m}$ are in the range of $22-$ $35 \mathrm{~cm} \mathrm{~s}^{-1}$ (Patro et al., 2002). Bubble plumes formed by breaking waves penetrate to depths of at least ca. $20-30 \mathrm{~cm}$ or more (Melville, 1996; Deane and Stokes, 2002), so if equilibrium is reached within less than $1 \mathrm{~s}$, the exposure time will be sufficient to reach or nearly reach equilibrium for many ocean bubbles. Furthermore, if equilibrium is approached, but not fully achieved, the relationship of surface coverage and bulk concentration may still be represented by a Langmuir isotherm curve (using appropriately adjusted parameters) with fidelity sufficient for application in an Earth system model. This is supported by calculations of the kinetics 
of convective-diffusive transport of surfactants to bubble surfaces, and subsequent adsorption (Jachimska et al., 2001).

Because the timescales of surfactant equilibrium in the ocean are similar to or less than bubble rise times in many cases, the assumption of equilibrium is a reasonable and useful first approximation for the purpose of representing bubble adsorption in Earth System models. Further investigation is required to determine under which conditions the assumed Langmuir equilibrium ceases to be a satisfactory approximation, particularly in regards to the equilibrium between competing surfactants (Mulqueen et al., 2001b, a).

\subsubsection{Effects of particle size and wind speed}

Our model does not yet include the effects of two important physical parameters, particle size and wind speed, on submicron SSA OM fraction. The fraction of organic matter in nascent sea spray increases dramatically for smaller particles (Oppo et al., 1999; Keene et al., 2007; Facchini et al., 2008). Although the exact mechanisms driving the functional relationship between OM fraction and size of nascent particles are not fully understood, empirical functions can be used in order to implement the parameterization into an atmospheric model (Gantt et al., 2011). Some researchers hypothesize that the formation of the SML under very calm conditions may result in higher organic enrichment being observed at low wind speeds (Gantt et al., 2011). Laboratory experiments in which organic aerosol is produced from generated waves under different wind speed and wave state conditions could aid in testing this assumption.

\subsubsection{Adsorption parameters and neglected adsorption processes}

We have utilized adsorption parameters obtained primarily at room temperature, but we have applied these values globally across a range of sea-surface temperatures. This assumption is justified to a certain extent by laboratory measurements. For example, for the proteins reviewed here, the observed dependence of the surface coverage on temperature is small between room temperature and $0{ }^{\circ} \mathrm{C}$ (Graham and Phillips, $1979 \mathrm{a}, \mathrm{b}, \mathrm{c})$. However, it is not clear whether the adsorption constants of marine biomolecules are, in general, sensitive to sea-surface temperature. Laboratory constraints on adsorption parameters for a variety of marine biomolecules or proxies across the entire temperature range $0-30{ }^{\circ} \mathrm{C}$ will be needed in order to understand how temperature affects the emission process, particularly in polar oceans.

In addition to parameter uncertainties, several processes have been neglected that may prove important to marine organic enrichment. Perhaps most importantly, we have neglected the role of marine aggregates (Facchini et al., 2008) in driving interfacial adsorption. Further study is needed to derive a parameterization of the colloid formation process appropriate for inclusion into a global model.
We have also neglected interactions between groups of molecules at the bubble surface. For example, some polysaccharides that do not adsorb to the air-water interface on their own may do so in cooperation with proteins (Baeza et al., 2005). Laboratory studies examining the interactions of appropriate marine proxy molecules at the air-water interface may help to advance understanding and provide quantitative constraints on this process.

Finally, we have not yet accounted for the observed greater enrichment of the particulate phase relative to the dissolved phase in the SML (Marty et al., 1988; Kuznetsova and Lee, 2002; Kuznetsova et al., 2005). This phenomenon may be driven by chemical adsorption processes, or by the more efficient scavenging of larger particles from the water column due to bubble impaction. (Sutherland, 1948; Weber et al., 1983; Dai et al., 1998, 2000).

\subsubsection{Observational constraints needed from field studies}

Currently, only very limited observations of organic matter are available from field studies, and these observations are frequently not easily intercomparable, due to differences in the experimental methods used. Several measurement techniques for studying the organic composition of ambient marine aerosol particles have recently been reviewed and directly compared by Frossard et al. (2014b). An ideal tool for model evaluation would be a long-term, consistent database of observations of the organic composition of submicron aerosol, sea-surface microlayer, and subsurface water across a variety of ocean ecosystems. Methods that provide more detailed but also quantitative chemical information can increase the ability to distinguish between different chemical classes of organic matter and help to advance understanding of the underlying processes that determine the distribution and composition of marine organic matter. While complete molecular characterization may not be possible, measurement of functional group composition (e.g., by FTIR as shown here) can begin to provide clues into chemical processes. Recent work has shown that sea spray aerosol generated from productive seawater had a greater fraction of alkane functional groups (as measured by FTIR), compared to aerosol generated from nonproductive seawater (Frossard et al., 2014a).

One geographic region that is a traditional focus of field campaigns is the North Atlantic Basin. Additional observations there, during the peak of the spring bloom, may prove essential to resolving the apparent contradiction between the view that the organic mass fraction of submicron aerosol is essentially constant (Quinn et al., 2014) and the view that it dramatically changes over the coarse of a strong bloom (O'Dowd et al., 2004; Rinaldi et al., 2013).

Finally, SFG measurements of the detailed surface chemistry of natural and artificial ocean surfaces and sea spray particles (Ault et al., 2013; Ebben et al., 2013; Laß et al., 
2013) are an emerging approach that is very intriguing. Further such studies could prove valuable in identifying important marine surfactants and distinguishing their role in ocean biochemical processes as well as their molecular interactions and orientations at the ocean surface and particle surfaces.

\subsubsection{Uncertainties in the underlying ocean biogeochemistry simulations}

The model's predictive capability is inherently limited by the underlying ocean biogeochemistry model. Global ocean biogeochemistry models currently have a limited ability to accurately predict the exact location and timing of phytoplankton blooms (Doney et al., 2009). While the model has some difficulty in exactly reproducing the location and timing of phytoplankton blooms, the patchiness of the active phytoplankton blooms is a realistic qualitative feature. These blooms can be extremely localized, as can also be seen in satellite-derived maps of chlorophyll. This leads to highly localized distributions of the lipid-like class and of OM fraction in our model (Figs. 6a, 7).

Active development of the ocean biogeochemistry model is underway, and it is hoped that the model's skill may improve in the future. Additionally, it should be considered whether more sophisticated metrics can be applied to assess the skill of ocean biogeochemistry simulations. Because of the highly localized nature of phytoplankton blooms, approaches such as object-based verification or fuzzy verification could be considered, which are used in verification of hurricane and precipitation forecasts. These approaches may produce a more meaningful assessment of the model's ability to simulate realistic blooms if their location or timing is slightly mismatched.

\section{Conclusions}

In this study, we have introduced a novel framework for the parameterization of the organic fraction of SSA.

The framework predicts the mass of mixtures of organic components with different surface activity (Langmuir coefficient $\alpha_{i}$ ), molecular mass $M_{i}$, and surface packing (maximum surface excess $\Gamma_{i, \infty}$ ), in competitive equilibrium with each other. This framework represents an initial step towards linking information available in ocean biogeochemical models to emission parameterizations for global atmospheric chemistry and climate models. Because the enrichment behavior is dominated primarily by two macromolecule classes, lipids and proteins, a two-component model may prove sufficient to capture one important dimension of the geographic variation in ocean biogeochemistry: the differences between regions of high and low biological productivity.

We have reviewed evidence that organic enrichment in the SML and in sea spray aerosol are chemically specific in consistent ways, and that there is a selectively stronger enrichment of larger particles in the SML. Using a conceptually straightforward model, we have emphasized that high organic mass fractions in the submicron aerosol can be obtained only when strongly adsorbing materials are present in sufficiently high concentrations. By contrast, the concentration of weakly or nonadsorbing organic matter in the bulk ocean plays only a minor or negligible role in determining total OM concentrations in nascent sea spray.

Using output from an ocean biogeochemistry model, we derived estimates of the distributions of five classes of macromolecules, and selected a model compound to represent the physical and chemical properties of each class. This allows us to simulate global patterns in OM fractions. Predicted $\mathrm{OM}$ : chl $a$ relationships at high chl $a$ levels resemble existing empirical parameterizations derived from observations at coastal sites, but are derived independently using ocean biogeochemistry model output fields. Further observations are needed to better constrain the spatial and seasonal variability in these relationships, particularly outside of strong seasonal plankton blooms.

The simulated ratios of different macromolecular classes in the aerosol are highly sensitive to the assumed adsorptivity constants within the large range of uncertainty explored here. Chemically resolved observations of the sea spray aerosol may help to constrain the values of these parameters, although contradictions currently exist with the limited set of measurements examined here. Specifically, FTIR measurements from the Southeast Pacific agree best with the BASE case estimate while FTIR measurements from the North Atlantic and Arctic agree best with the LOW-LIP+HIGHPOLY case. These discrepancies deserve further investigation.

Because concentrations of surface-active compounds correlate with chl $a$ during strong phytoplankton blooms, our model shows that adsorption-driven enrichment of organic matter in sea spray is correlated with chlorophyll concentrations during blooms. However, the same chl $a$ concentration may correspond to different film OM fractions in different regions and seasons. Parameterizations of the spray aerosol organic fraction that rely solely on chlorophyll are likely to underestimate organic enrichment in regions where chlorophyll is low, but moderately surface-active compounds with intermediate biogeochemical lifetimes are still present. Our model suggests that in regions where aerosol OC is dominated by semilabile compounds rather than labile compounds, the seasonal cycle in the OM fraction may actually be anticorrelated with chl $a$, because peak SDOC concentrations occur a few months later than peak chl $a$ concentrations.

Prediction of ocean and aerosol organic films is also of potential interest for several further reasons in the context of global change. When organics make up a large fraction of the aerosol mass, under some conditions the organic molecules may form a solid or semisolid layer covering the aerosol surface, kinetically delaying water uptake by reducing either the mass accommodation coefficient (Takahama et al., 2010) or 
the bulk diffusion coefficient within the aerosol particle (Shiraiwa et al., 2013). Ocean films can inhibit the exchange of gases across the air-sea interface and , in particular, they can slow ocean uptake of carbon dioxide (Frew et al., 1990; Frew, 1997; Tsai and Liu, 2003; Wanninkhof et al., 2009). Furthermore, the thickness of ocean interfacial films may influence the size distribution of sea spray. For example, soluble surfactants can stabilize bubble surfaces, such that greater film drainage and thinning occurs prior to bursting (Spiel, 1997; Oppo et al., 1999; Russell et al., 2010; Modini et al., 2013).

We conclude that variations in the concentration of highly surface-active compounds associated with primary production and possibly marine particle size, rather than bulk TOC (total organic carbon) concentrations, drive a portion of the spatial and temporal variability of the submicron sea spray organic mass fraction. Future work should focus on improving constraints on the impacts of marine surface chemistry on SSA production through laboratory experiments and empirical fitting to field observations. The dependence of SSA composition on particle size and wind speed should be investigated. Atmospheric implications should be explored, including impacts on $\mathrm{CCN}$ activity.

\section{The Supplement related to this article is available online at doi:10.5194/acp-14-13601-2014-supplement.}

Acknowledgements. This research was supported by the Office of Science of the US Department of Energy as part of the Earth System Modeling Program, and by the SciDAC project ACES4BGC - Applying Computationally Efficient Schemes for Biogeochemical Cycles. The Pacific Northwest National Laboratory is operated for DOE by Battelle Memorial Institute under contract DE-AC0576RL01830.

We thank Mathew Maltrud for running the CESM simulations from which we used the output fields for this analysis, and the many scientists who have contributed to the development of the POP/BEC components of the CESM model.

We would like to thank several colleagues for providing chemical composition data for comparison with the model: Brett Gantt for use of the Point Reyes data, and Matteo Rinaldi, M. Cristina Facchini (CNR-ISAC), Darius Ceburnis and Colin O'Dowd (NUIG) for use of the Mace Head data. The conclusions presented in this study are the authors' and do not necessarily reflect the views of these groups.

Brett Gantt and two anonymous referees provided detailed reviews of this manuscript, which lead to significant improvements.

We thank Kim Prather, Grant Deane, and Dale Stokes for fruitful and stimulating conversations that inspired our interest and informed our development of ideas on the effects of surface chemistry on sea spray formation.

The authors wish to acknowledge use of the Ferret program for analysis and graphics in this paper. Ferret is a product of NOAA's Pacific Marine Environmental Laboratory (information is available at http://ferret.pmel.noaa.gov/Ferret/).

Edited by: P. Monks

\section{References}

Adamson, A. W. and Gast, A. P.: Physical chemistry of surfaces, Wiley Interscience, New York, 808 pp., 1997.

Albert, M. F. M. A., Schaap, M., Manders, A. M. M., Scannell, C., O'Dowd, C. D., and de Leeuw, G.: Uncertainties in the determination of global sub-micron marine organic matter emissions, Atmos. Environ., 57, 289-300, 2012.

Alexander, D. M., Barnes, G. T., McGregor, M. A., and Walker, K.: The penetration of monolayers by surfactants, edited by: Scamehorn, J., in: vol. 311 of ACS Symposium Series, chap. 10, 133-142, American Chemical Society, Washington, DC, doi:10.1021/bk-1986-0311.ch010, 1986.

Amon, R. M. W. and Benner, R.: Bacterial utilization of different size classes of dissolved organic matter, Limnol. Oceanogr., 41, 41-51, 1996.

Armstrong, R. A., Lee, C., Hedges, J. I., Honjo, S., and Wakeham, S. G.: A new, mechanistic model for organic carbon fluxes in the ocean based on the quantitative association of POC with ballast minerals, Deep Sea Research Part II: Topical Studies in Oceanography, 49, 219-236, 2001.

Ault, A. P., Zhao, D., Ebben, C. J., Tauber, M. J., Geiger, F. M., Prather, K. A., and Grassian, V. H.: Raman microspectroscopy and vibrational sum frequency generation spectroscopy as probes of the bulk and surface compositions of size-resolved sea spray aerosol particles, PCCP Phys. Chem. Ch. Ph., 15, 6206-6214, 2013.

Averett, R. C., Leenheer, J. A., McKnight, D. M., and Thorn, K. A.: Humic substances in the Suwanee River, Georgia: Interactions, properties, and proposed structures, Tech. Rep. Open-File Report 87-557, US Geological Survey, Denver, Colorado, 225 pp., 1989.

Azetsu-Scott, K. and Passow, U.: Ascending marine particles: Significance of transparent exopolymer particles (TEP) in the upper ocean, Limnol. Oceanogr., 49, 741-748, 2004.

Babak, V., Skotnikova, E., Lukina, I., Pelletier, S., Hubert, P., and Dellacherie, E.: Hydrophobically associating alginate derivatives: surface tension properties of their mixed aqueous solutions with oppositely charged surfactants, J. Colloid Interf. Sci., 225, 505-510, 2000.

Baeza, R., Carrera Sanchez, C., Pilosof, A. M., and Rodríguez Patino, J. M.: Interactions of polysaccharides with $\beta$ lactoglobulin adsorbed films at the air-water interface, Food Hydrocolloid., 19, 239-248, 2005.

Barger, W. R. and Means, J. C.: Clues to the structure of marine organic material from the study of physical properties of surface films, in: Marine and Estuarine Geochemistry, edited by: Sigleo, A. C. and Hattori, A., Lewis Publishers, Chelsea, Michigan, 4767, 340 pp., 1985

Bates, T. S., Quinn, P. K., Frossard, A. A., Russell, L. M., Hakala, J., Petäjä, T., Kulmala, M., Covert, D. S., Cappa, C. D., Li, S.-M., Hayden, K. L., Nuaaman, I., McLaren, R., Massoli, P., Canagaratna, M. R., Onasch, T. B., Sueper, D., Worsnop, D. R., and Keene, W. C.: Measurements of ocean derived aerosol off the coast of California, J. Geophys. Res., 117, D00V15, doi:10.1029/2012JD017588, 2012.

Benner, R.: Biogeochemistry of Dissolved Organic Matter, chap. Chemical composition and reactivity, edited by: Hansell, D. and Carlson, C., 59-90, Academic Press, New York, , 2002.

Blanchard, D. C.: Bubble Scavenging and the Water-to-Air Transfer of Organic Material in the Sea, in: Applied chemistry at protein 
interfaces, edited by: Baier, R. E., 360-387, American Chemical Society, Washington, DC, 1975.

Blanchard, D. C.: The ejection of drops from the sea and their enrichment with bacteria and other materials: A review, Estuaries, 12, 127-137, doi:10.2307/1351816, 1989.

Blanchard, D. C. and Syzdek, L. D.: Water-to-air transfer and enrichment of bacteria in drops from bursting bubbles, Appl. Environ. Microb., 43, 1001-1005, http://aem.asm.org/cgi/content/ abstract/43/5/1001, 1982.

Blanchard, D. C. and Syzdek, L. D.: Film drop production as a function of bubble size, J. Geophys. Res.-Oceans (1978-2012), 93, 3649-3654, 1988.

Brzozowska, A. M., Duits, M. H. G., and Mugele, F.: Stability of stearic acid monolayers on Artificial Sea Water, Colloids and Surfaces A: Physicochemical and Engineering Aspects, 407, 3848, 2012.

Buonassissi, C. and Dierssen, H.: A regional comparison of particle size distributions and the power law approximation in oceanic and estuarine surface waters, J. Geophys. Res., 115, C10028, doi:10.1029/2010JC006256, 2010.

Burrows, S. M., Hoose, C., Pöschl, U., and Lawrence, M. G.: Ice nuclei in marine air: biogenic particles or dust?, Atmos. Chem. Phys., 13, 245-267, doi:10.5194/acp-13-245-2013, 2013.

Buseck, P. R. and Pósfai, M.: Airborne minerals and related aerosol particles: Effects on climate and the environment, P Natl. Acad. Sci. USA, 96, 3372-3379, 1999.

Carlson, C.: Biogeochemistry of Dissolved Organic Matter, chap. Production and removal processes, edited by: Hansell, D. and Carlson, C. , 91-139, Academic Press, New York, 2002.

Carlson, C. A., Hansell, D. A., Peltzer, E. T., and Smith Jr, W. O.: Stocks and dynamics of dissolved and particulate organic matter in the southern Ross Sea, Antarctica, Deep Sea Research Part II: Topical Studies in Oceanography, 47, 3201-3225, 2000.

Carslaw, K. S., Boucher, O., Spracklen, D. V., Mann, G. W., Rae, J. G. L., Woodward, S., and Kulmala, M.: A review of natural aerosol interactions and feedbacks within the Earth system, Atmos. Chem. Phys., 10, 1701-1737, doi:10.5194/acp-10-17012010, 2010.

Christian, J. and Anderson, T.: Biogeochemistry of Dissolved Organic Matter, chap. Modeling DOM biogeochemistry, edited by: Hansell, D. and Carlson, C., 717-756, Academic Press, New York, 2002.

Christodoulou, A. P. and Rosano, H. L.: Effect of $\mathrm{pH}$ and nature of monovalent cations on surface isotherms of saturated $C_{16}$ to $C_{22}$ soap monolayers, Adv. Chem. Ser, 84, 210-234, 1968.

Collins, D. B., Ault, A. P., Moffet, R. C., Ruppel, M. J., CuadraRodriguez, L. A., Guasco, T. L., Corrigan, C. E., Pedler, B. E., Azam, F., Aluwihare, L. I., Bertram, T. H., Roberts, G. C., Grassian, V. H., and Prather, K. A.: Impact of marine biogeochemistry on the chemical mixing state and cloud forming ability of nascent sea spray aerosol, J. Geophys. Res.-Atmos., 118, 85538565, doi:10.1002/jgrd.50598, 2013.

Cook, M. A. and Talbot, E. L.: Surface Hydrolysis in Sodium Lauryl Sulfate Solutions and its Effect on Surface Tension and on Adsorption at the SolidAqueous Solution Interface, The Journal of Physical Chemistry, 56, 412-416, 1952.

Croot, P., Passow, U., Assmy, P., Jansen, S., and Strass, V.: Surface active substances in the upper water column during a South- ern Ocean Iron Fertilization Experiment (EIFEX), Geophys. Res. Lett., 34, L03612, doi:10.1029/2006GL028080, 2007.

Cunliffe, M., Engel, A., Frka, S., Gašparović, B., Guitart, C., Murrell, J. C., Salter, M., Stolle, C., Upstill-Goddard, R., and Wurl, O.: Sea surface microlayers: a unified physicochemical and biological perspective of the air-ocean interface, Prog. Oceanogr., 109, 104-116, doi:10.1016/j.pocean.2012.08.004, 2012.

Dai, Z., Dukhin, S., Fornasiero, D., and Ralston, J.: The inertial hydrodynamic interaction of particles and rising bubbles with mobile surfaces, J. Colloid Interf. Sci., 197, 275-292, 1998.

Dai, Z., Fornasiero, D., and Ralston, J.: Particle-bubble collision models - a review, Adv. Colloid Interfac., 85, 231-256, 2000.

Damodaran, S. and Razumovsky, L.: Competitive adsorption and thermodynamic incompatibility of mixing of $\beta$-casein and gum arabic at the air-water interface, Food hydrocolloid., 17, 355363, 2003.

Deane, G. and Stokes, M.: Scale dependence of bubble creation mechanisms in breaking waves, Nature, 418, 839-844, 2002.

Dinar, E., Taraniuk, I., Graber, E. R., Katsman, S., Moise, T., Anttila, T., Mentel, T. F., and Rudich, Y.: Cloud Condensation Nuclei properties of model and atmospheric HULIS, Atmos. Chem. Phys., 6, 2465-2482, doi:10.5194/acp-6-2465-2006, 2006.

Dittmar, T. and Kattner, G.: Recalcitrant dissolved organic matter in the ocean: major contribution of small amphiphilics, Mar. Chem., 82, 115-123, 2003.

Doney, S. C., Lima, I., Moore, J. K., Lindsay, K., Behrenfeld, M. J., Westberry, T. K., Mahowald, N., Glover, D. M., and Takahashi, T.: Skill metrics for confronting global upper ocean ecosystembiogeochemistry models against field and remote sensing data, J. Marine Syst., 76, 95-112, 2009.

Ebben, C. J., Ault, A. P., Ruppel, M. J., Ryder, O. S., Bertram, T. H., Grassian, V. H., Prather, K. A., and Geiger, F. M.: Size-Resolved Sea Spray Aerosol Particles Studied by Vibrational Sum Frequency Generation, The Journal of Physical Chemistry A, 117, 6589-6601, 2013.

Elliott, S.: Dependence of DMS global sea-air flux distribution on transfer velocity and concentration field type, J. Geophys. Res., 114, G02001, doi:10.1029/2008JG000710, 2009.

Elliott, S., Maltrud, M., Reagan, M., Moridis, G., and CameronSmith, P.: Marine methane cycle simulations for the period of early global warming, J. Geophys. Res., 116, G01010, doi:10.1029/2010JG001300, 2011.

Elliott, S., Burrows, S., Deal, C., Liu, X., Long, M., Ogunro, O., Russell, L., and Wingenter, O.: Prospects for simulating macromolecular surfactant chemistry at the ocean-atmosphere boundary, Environ. Res. Lett., 9, 064012, doi:10.1088/17489326/9/6/064012, 2014.

Facchini, M. C., Rinaldi, M., Decesari, S., Carbone, C., Finessi, E., Mircea, M., Fuzzi, S., Ceburnis, D., Flanagan, R., Nilsson, E. D., de Leeuw, G., Martino, M., Woeltjen, J., and O'Dowd, C. D.: Primary submicron marine aerosol dominated by insoluble organic colloids and aggregates, Geophys. Res. Lett., 35, L17814, doi:10.1029/2008GL034210, 2008.

Fraga, F.: Phytoplanktonic biomass synthesis: application to deviations from Redfield stoichiometry, Scientia Marina, 65, 153-169, 2001.

Frew, N. M.: The Sea Surface and Global Change, chap. The role of organic films in air-sea gas exchange, edited by: Liss, P. S. and 
Duce, R. A., 121-171, Cambridge University Press, Cambridge, UK, 1997.

Frew, N. M., Goldman, J. C., Dennett, M. R., and Johnson, A. S.: Impact of phytoplankton-generated surfactants on air-sea gas exchange, J. Geophys. Res.-Oceans (1978-2012), 95, 3337-3352, 1990.

Frossard, A. A., Russell, L. M., Burrows, S. M., Elliott, S. M., Bates, T. S., and Quinn, P. K.: Sources and composition of submicron organic mass in marine aerosol particles, J. Geophys. Res. Atmos., 119, doi::10.1002/2014JD021913, 2014a.

Frossard, A. A., Russell, L. M., Massoli, P., Bates, T. S., and Quinn, P. K.: Side-by-Side Comparison of Four Techniques Explains the Apparent Differences in the Organic Composition of Generated and Ambient Marine Aerosol Particles, Aerosol Sci. Tech., 48, $\mathrm{v}-\mathrm{x}, 2014 \mathrm{~b}$.

Fuentes, E., Coe, H., Green, D., de Leeuw, G., and McFiggans, G.: Laboratory-generated marine aerosol via bubble-bursting and atomization, Atmos. Meas. Tech., 3, 141-162, doi:10.5194/amt-3141-2010, 2010a.

Fuentes, E., Coe, H., Green, D., de Leeuw, G., and McFiggans, G.: On the impacts of phytoplankton-derived organic matter on the properties of the primary marine aerosol - Part 1: Source fluxes, Atmos. Chem. Phys., 10, 9295-9317, doi:10.5194/acp-10-92952010, 2010.b.

Fuentes, E., Coe, H., Green, D., and McFiggans, G.: On the impacts of phytoplankton-derived organic matter on the properties of the primary marine aerosol - Part 2: Composition, hygroscopicity and cloud condensation activity, Atmos. Chem. Phys., 11, 25852602, doi:10.5194/acp-11-2585-2011, 2011.

Gantt, B. and Meskhidze, N.: The physical and chemical characteristics of marine primary organic aerosol: a review, Atmos. Chem. Phys., 13, 3979-3996, doi:10.5194/acp-13-3979-2013, 2013.

Gantt, B., Meskhidze, N., Facchini, M. C., Rinaldi, M., Ceburnis, D., and O'Dowd, C. D.: Wind speed dependent size-resolved parameterization for the organic mass fraction of sea spray aerosol, Atmos. Chem. Phys., 11, 8777-8790, doi:10.5194/acp-11-87772011, 2011.

Gaonkar, A. G.: Surface and interfacial activities and emulsion characteristics of some food hydrocolloids, Food Hydrocolloid., 5, 329-337, 1991.

Gardner, W., Mishonov, A., and Richardson, M.: Global POC concentrations from in-situ and satellite data, Deep Sea Research Part II: Topical Studies in Oceanography, 53, 718-740, 2006.

Garrett, W. D.: Stabilization of air bubbles at the air-sea interface by surface-active material, Deep Sea Research and Oceanographic Abstracts, 14, 661-672, doi:10.1016/S0011-7471(67)80004-4, 1967.

Garrett, W. D.: The influence of monomolecular surface films on the production of condensation nuclei from bubbled sea water, J. Geophys. Res., 73, 5145-5150, 1968.

Garrett, W. D.: Organic chemistry of natural sea surface films, in: Organic Matter in Natural Waters, edited by: Hood, D., 469-477, Inst. Mar. Sci. Occas. Publ. 1, Univ. Alaska, Fairbanks, 1970.

Gašparović, B. and Ćosović, B.: Surface-active properties of organic matter in the North Adriatic Sea, Estuarine, Coastal and Shelf Science, 58, 555-566, 2003.

Gašparović, B., Kozarac, Z., Saliot, A., Ćosović, B., and Möbius, D.: Physicochemical Characterization of Natural and ex-Situ Re- constructed Sea-Surface Microlayers, J. Colloid Interf. Sci., 208, 191-202, 1998.

Gašparović, B. and Ćosović, B.: Distribution of surface-active substances in the northern Adriatic Sea, Mar. Chem., 75, 301-313, 2001.

Giribabu, K. and Ghosh, P.: Adsorption of nonionic surfactants at fluid-fluid interfaces: Importance in the coalescence of bubbles and drops, Chemical engineering science, 62, 3057-3067, 2007.

Graham, D. E. and Phillips, M. C.: Proteins at liquid interfaces: I. Kinetics of adsorption and surface denaturation, J. Colloid Interf., 70, 403-414, 1979a.

Graham, D. E. and Phillips, M. C.: Proteins at liquid interfaces: II. Adsorption isotherms, J. Colloid Interf., 70, 415-426, 1979b.

Graham, D. E. and Phillips, M. C.: Proteins at liquid interfaces: III. Molecular structures of adsorbed films, Journal of Colloid and Interface Science, 70, 427-439, 1979c.

Gregg, W. W., Ginoux, P., Schopf, P. S., and Casey, N. W.: Phytoplankton and iron: validation of a global three-dimensional ocean biogeochemical model, Deep Sea Research Part II: Topical Studies in Oceanography, 50, 3143-3169, 2003.

Hansell, D. A.: Recalcitrant dissolved organic carbon fractions, Annual Review of Marine Science, 5, 421-445, 2013.

Hansell, D. A., Carlson, C. A., and Schlitzer, R.: Net removal of major marine dissolved organic carbon fractions in the subsurface ocean, Global Biogeochemical Cycles, 26, GB1016, doi:10.1029/2011GB004069, 2012.

Harper, K. L. and Allen, H. C.: Competition between DPPC and SDS at the Air-Aqueous Interface, Langmuir, 23, 8925-8931, 2007.

Hawkins, L. and Russell, L.: Polysaccharides, proteins, and phytoplankton fragments: four chemically distinct types of marine primary organic aerosol classified by single particle spectromicroscopy, Adv. Meteorol, 2010, 612132, doi:10.1155/2010/612132, 2010.

Hawkins, L. N., Russell, L. M., Covert, D. S., Quinn, P. K., and Bates, T. S.: Carboxylic acids, sulfates, and organosulfates in processed continental organic aerosol over the southeast Pacific Ocean during VOCALS-REx 2008, J. Geophys. Res., 115, D13201, doi:10.1029/2009JD013276, 2010.

Hedges, J. I., Baldock, J. A., Gelinas, Y., Lee, C., Peterson, M., and Wakeham, S. G.: Evidence for non-selective preservation of organic matter in sinking marine particles, Nature, 409, 801-804, 2001.

Heikkila, R. E., Deamer, D. W., and Cornwell, D. G.: Solution of fatty acids from monolayers spread at the air-water interface: identification of phase transformations and the estimation of surface charge, J. Lipid Res., 11, 195-200, 1970.

Hubberten, U., Lara, R. J., and Kattner, G.: Amino acid composition of seawater and dissolved humic substances in the Greenland Sea, Mar. Chem., 45, 121-128, 1994.

Hultin, K., Krejci, R., Pinhassi, J., Gomez-Consarnau, L., Mårtensson, E., Hagström, A., and Nilsson, E.: Aerosol and bacterial emissions from Baltic Seawater, Atmos. Res., 99, 1-14, 2011.

Hultin, K. A., Nilsson, E. D., Krejci, R., Mårtensson, E. M., Ehn, M., Hagström, A., and de Leeuw, G.: In situ laboratory sea spray production during the Marine Aerosol Production 2006 cruise on the northeastern Atlantic Ocean, J. Geophys. Res., 115, D06201, doi:10.1029/2009JD012522, 2010. 
Hurrell, J. W., Holland, M., Gent, P. R., Ghan, S., Kay, J. E., Kushner, P. J., Lamarque, J.-F., Large, W., Lawrence, D., Lindsay, K., Lipscomb, W. H., Long, M. C., Mahowald, N., R., M. D., Neale, R. B., Rasch, P. J., Vavrus, S., Vertenstein, M., Bader, D., Collins, W., Hack, J., Kiehl, J., and Marshall, S.: The Community Earth System Model: A Framework for Collaborative Research, B. Am. Meteorol. Soc., 94, 1339-1360, doi:10.1175/BAMS-D12-00121.1, 2013.

Ittekkot, V.: Variations of dissolved organic matter during a plankton bloom: qualitative aspects, based on sugar and amino acid analyses, Marine Chemistry, 11, 143-158, 1982.

Jachimska, B., Warszynski, P., and Malysa, K.: Influence of adsorption kinetics and bubble motion on stability of the foam films formed at $n$-octanol, $n$-hexanol and $n$-butanol solution surface, Colloids and Surfaces A: Physicochemical and Engineering Aspects, 192, 177-193, 2001.

Jarvis, N. L., Garrett, W. D., Scheiman, M. A., and Timmons, C. O.: Surface chemical characterization of surface active material in seawater, Limnol. Oceanogr., 12, 88-97, 1967.

Johnson, B. D. and Wangersky, P. J.: Microbubbles: Stabilization by monolayers of adsorbed particles, J. Geophys. Res.-Oceans (1978-2012), 92, 14641-14647, 1987.

Kaiser, K. and Benner, R.: Biochemical composition and size distribution of organic matter at the Pacific and Atlantic time-series stations, Marine Chemistry, 113, 63-77, 2009.

Karydis, V. A., Capps, S. L., Russell, A. G., and Nenes, A.: Adjoint sensitivity of global cloud droplet number to aerosol and dynamical parameters, Atmos. Chem. Phys., 12, 9041-9055, doi:10.5194/acp-12-9041-2012, 2012.

Keene, W. C., Sander, R., Pszenny, A. A., Vogt, R., Crutzen, P. J., and Galloway, J. N.: Aerosol pH in the marine boundary layer: A review and model evaluation, J. Aerosol Sci., 29, 339-356, 1998.

Keene, W. C., Maring, H., Maben, J. R., Kieber, D. J., Pszenny, A. A. P., Dahl, E. E., Izaguirre, M. A., Davis, A. J., Long, M. S., Zhou, X., Smoydzin, L., and Sander, R.: Chemical and physical characteristics of nascent aerosols produced by bursting bubbles at a model air-sea interface, J. Geophys. Res.-Atmos., 112, D21202, doi:10.1029/2007JD008464, 2007.

Krzan, M., Zawala, J., and Malysa, K.: Development of steady state adsorption distribution over interface of a bubble rising in solutions of n-alkanols (C5, C8) and n-alkyltrimethylammonium bromides (C8, C12, C16), Colloids and Surfaces A: Physicochemical and Engineering Aspects, 298, 42-51, 2007.

Kujawinski, E. B., Farrington, J. W., and Moffett, J. W.: Evidence for grazing-mediated production of dissolved surface-active material by marine protists, Mar. Chem., 77, 133-142, 2002.

Kuznetsova, M. and Lee, C.: Dissolved free and combined amino acids in nearshore seawater, sea surface microlayers and foams: Influence of extracellular hydrolysis, Aquatic sciences, 64, 252268, 2002.

Kuznetsova, M., Lee, C., Aller, J., and Frew, N.: Enrichment of amino acids in the sea surface microlayer at coastal and open ocean sites in the North Atlantic Ocean, Limnol. Oceanogr., 49, 1605-1619, doi:10.4319/lo.2004.49.5.1605, 2004.

Kuznetsova, M., Lee, C., and Aller, J.: Characterization of the proteinaceous matter in marine aerosols, Mar. Chem., 96, 359-377, doi:10.1016/j.marchem.2005.03.007, 2005.

Lan, Q., Bassi, A. S., Zhu, J.-X. J., and Margaritis, A.: A modified Langmuir model for the prediction of the effects of ionic strength on the equilibrium characteristics of protein adsorption onto ion exchange/affinity adsorbents, Chem. Eng. J., 81, 179-186, 2001.

Langmuir, I.: The adsorption of gases on plane surfaces of glass, mica and platinum., J. Am. Chem. Soc., 40, 1361-1403, 1918.

Large, W. G., McWilliams, J. C., and Doney, S. C.: Oceanic vertical mixing: A review and a model with a nonlocal boundary layer parameterization, Rev. Geophys., 32, 363-403, 1994.

Laß, K., Bange, H. W., and Friedrichs, G.: Seasonal signatures in SFG vibrational spectra of the sea surface nanolayer at Boknis Eck Time Series Station (SW Baltic Sea), Biogeosciences, 10, 5325-5334, doi:10.5194/bg-10-5325-2013, 2013.

Lehninger, A. L.: Biochemistry: The molecular basis of cell structure and function, Worth Publishers, Inc., second edition, 1104 pp., New York, 1975.

Lewis, R. and Schwartz, E.: Sea salt aerosol production: mechanisms, methods, measurements and models - a critical review, vol. 152, American Geophysical Union, Washington, DC, 413 pp., 2004.

Li, Z., Williams, A. L., and Rood, M. J.: Influence of soluble surfactant properties on the activation of aerosol particles containing inorganic solute, J. Atmos. Sci., 55, 1859-1866, 1998.

Lindsley, W., Skop, R., and Brown, J.: Surface pressure and wavedamping effects of surface-active organic compounds on seawater, Ocean engineering, 18, 593-601, 1991.

Lomas, M. W., Glibert, P. M., Clougherty, D. A., Huber, D. R., Jones, J., Alexander, J., and Haramoto, E.: Elevated organic nutrient ratios associated with brown tide algal blooms of Aureococcus anophagefferens (Pelagophyceae), J. Plankton Res., 23, 1339-1344, 2001.

Long, M. S., Keene, W. C., Kieber, D. J., Erickson, D. J., and Maring, H.: A sea-state based source function for size- and composition-resolved marine aerosol production, Atmos. Chem. Phys., 11, 1203-1216, doi:10.5194/acp-11-1203-2011, 2011.

Longhurst, A. R.: Ecological Biogeography of the Sea, Academic Press, San Diego, 398 pp., 1998.

Macintyre, F.: Geochemical fractionation during mass transfer from sea to air by breaking bubbles, Tellus, 22, 451-462, 1970.

Malcolm, R. L.: The uniqueness of humic substances in each of soil, stream and marine environments, Anal. Chim. Acta, 232, 19-30, 1990.

Maltrud, M. E., Smith, R. D., Semtner, A. J., and Malone, R. C.: Global eddy-resolving ocean simulations driven by 1985-1995 atmospheric winds, J. Geophys. Res.-Oceans (1978-2012), 103, 30825-30853, 1998.

Marty, J., Ẑutić, V., Precali, R., Saliot, A., Ćosović, B., Smodlaka, N., and Cauwet, G.: Organic matter characterization in the Northern Adriatic Sea with special reference to the sea surface microlayer, Mar. Chem., 25, 243-263, 1988.

McGregor, M. A. and Barnes, G.: Equilibrium penetration of monolayers VI: Cholesterol-cetrimonium bromide system, J. Pharm. Sci., 67, 1054-1056, 1978.

Melville, W.: The role of surface-wave breaking in air-sea interaction, Annual review of fluid mechanics, 28, 279-321, 1996.

Meskhidze, N. and Nenes, A.: Phytoplankton and cloudiness in the Southern Ocean, Science, 314, 1419-1423, 2006.

Modini, R. L., Russell, L. M., Deane, G. B., and Stokes, M. D.: Effect of soluble surfactant on bubble persistence and bubbleproduced aerosol particles, J. Geophys. Res.-Atmos., 10, 13881400, doi:10.1002/jgrd.50186, 2013. 
Moore, J. K., Doney, S. C., Kleypas, J. A., Glover, D. M., and Fung, I. Y.: An intermediate complexity marine ecosystem model for the global domain, Deep Sea Research Part II: Topical Studies in Oceanography, 49, 403-462, 2001.

Moore, J. K., Doney, S. C., and Lindsay, K.: Upper ocean ecosystem dynamics and iron cycling in a global threedimensional model, Global Biogeochemical Cycles, 18, GB4028, doi:10.1029/2004GB002220, 2004.

Moore, R. H., Ingall, E. D., Sorooshian, A., and Nenes, A.: Molar mass, surface tension, and droplet growth kinetics of marine organics from measurements of CCN activity, Geophys. Res. Lett., 35, L07801, doi:10.1029/2008GL033350, 2008.

Moore, R. H., Karydis, V. A., Capps, S. L., Lathem, T. L., and Nenes, A.: Droplet number uncertainties associated with CCN: an assessment using observations and a global model adjoint, Atmos. Chem. Phys., 13, 4235-4251, doi:10.5194/acp-13-42352013, 2013.

Mulqueen, M., Datwani, S. S., Stebe, K. J., and Blankschtein, D.: Dynamic surface tensions of aqueous surfactant mixtures: Experimental investigation, Langmuir, 17, 7494-7500, 2001a.

Mulqueen, M., Stebe, K. J., and Blankschtein, D.: Dynamic interfacial adsorption in aqueous surfactant mixtures: Theoretical study, Langmuir, 17, 5196-5207, 2001b.

Nagata, T.: Microbial Ecology of the Oceans, chap. Bacterial production and biomass in the oceans, edited by: Kirchman, D., Wiley Series in Ecological and Applied Microbiology, WileyBlackwell, New York, 2nd edn., 207-241, 2008.

Nilsson, L. and Bergenståhl, B.: Adsorption of hydrophobically modified starch at oil/water interfaces during emulsification, Langmuir, 22, 8770-8776, 2006.

O’Dowd, C., Langmann, B., Varghese, S., Scannell, C., Ceburnis, D., and Facchini, M.: A combined organic-inorganic sea-spray source function, Geophys. Res. Lett., 35, L01801, doi:10.1029/2007GL030331, 2008.

O'Dowd, C. D. and de Leeuw, G.: Marine aerosol production: a review of the current knowledge, Philosophical Transactions of the Royal Society A: Mathematical, Physical and Engineering Sciences, 365, 1753-1774, 2007.

O’Dowd, C. D., Facchini, M. C., Cavalli, F., Ceburnis, D., Mircea, M., Decesari, S., Fuzzi, S., Yoon, Y. J., and Putaud, J.: Biogenically driven organic contribution to marine aerosol, Nature, 431, 676-680, doi:10.1038/nature02959, 2004.

Ogunro, O. O., Burrows, S. M., Elliott, S. M., Frossard, A. A., Hoffman, F., Letscher, R. T., Moore, J. K., Russell, L. M., and Wingenter, W. O.: Global Distribution and Surface Activity of Macromolecules in Offline Simulations of Marine Organic Chemistry, submitted, 2014.

Oliver, M. J. and Irwin, A. J.: Objective global ocean biogeographic provinces, Geophys. Res. Lett., 35, L15601, doi:10.1029/2008GL034238, 2008.

Oppo, C., Bellandi, S., Degli Innocenti, N., Stortini, A., Loglio, G., Schiavuta, E., and Cini, R.: Surfactant components of marine organic matter as agents for biogeochemical fractionation and pollutant transport via marine aerosols, Mar. Chem., 63, 235-253, 1999.

Parra-Barraza, H., Burboa, M. G., Sánchez-Vázquez, M., Juárez, J., Goycoolea, F. M., and Valdez, M. A.: Chitosan-cholesterol and chitosan-stearic acid interactions at the air-water interface, Biomacromolecules, 6, 2416-2426, 2005.
Parrish, C. C.: Dissolved and particulate marine lipid classes: a review, Mar. Chem., 23, 17-40, 1988.

Parrish, C. C., Bodennec, G., Macpherson, E. J., and Ackman, R. G.: Seawater fatty acids and lipid classes in an urban and a rural Nova Scotia inlet, Lipids, 27, 651-655, 1992.

Parsons, T. R., Takahashi, M., and Hargrave, B.: Biological oceanographic processes, 3rd edition, Pergamon Press, New York, 344 pp., 1984.

Patro, R., Leifer, I., and Bowyer, P.: Better Bubble Process Modeling: Improved Bubble Hydrodynamics Parameterization, in: Gas Transfer at Water Surfaces, edited by: Donelan, M. A., Drennan, W. M., Saltzman, E. S., and Wanninkhof, R., American Geophysical Union, Washington, DC, doi:10.1029/GM127p0315, 315320, 2002.

Perez, A. A., Sánchez, C. C., Rodríguez Patino, J. M., Rubiolo, A. C., and Santiago, L. G.: Surface adsorption behaviour of milk whey protein and pectin mixtures under conditions of air - water interface saturation, Colloids and Surfaces B: Biointerfaces, 85, 306-315, 2011.

Prather, K. A., Bertram, T. H., Grassian, V. H., Deane, G. B., Stokes, M. D., DeMott, P. J., Aluwihare, L. I., Palenik, B. P., Azam, F., Seinfeld, J. H., Moffet, R. C., Molina, M. J., Cappa, C. D., Geiger, F. M., Roberts, G. C., Russell, L. M., Ault, A. P., Baltrusaitisc, J., Collins, D. B., Corrigan, C. E., Cuadra-Rodriguez, L. A., Ebben, C. J., Forestieri, S. D., Guasco, T. L., Hersey, S. P., Kim, M. J., Lambert, W. F., Modini, R. L., Mui, W., Pedler, B. E., Ruppel, M. J., Ryder, O. S., Schoepp, N. G., Sullivan, R. C., and Zhao, D.: Bringing the ocean into the laboratory to probe the chemical complexity of sea spray aerosol, P Natl. Acad. Sci. USA, 110, 7550-7555, doi:10.1073/pnas.1300262110, 2013.

Pszenny, A., Keene, W., Jacob, D., Fan, S., Maben, J., Zetwo, M., Springer-Young, M., and Galloway, J.: Evidence of inorganic chlorine gases other than hydrogen chloride in marine surface air, Geophys. Res. Lett., 20, 699-702, 1993.

Quinn, P. K., Bates, T. S., Schulz, K. S., Coffman, D., Frossard, A. A., Russell, L. M., Keene, W. C., and Kieber, D. J.: Contribution of sea surface carbon pool to organic matter enrichment in sea spray aerosol, Nature Geosci., 7, 228-232, 2014.

Resch, F. and Afeti, G.: Submicron film drop production by bubbles in seawater, J. Geophys. Res.-Oceans (1978-2012), 97, 36793683, 1992.

Rinaldi, M., Fuzzi, S., Decesari, S., Marullo, S., Santoleri, R., Provenzale, A., Hardenberg, J., Ceburnis, D., Vaishya, A., O'Dowd, C. D., and Facchini, M. C.: Is chlorophyll-a the best surrogate for organic matter enrichment in submicron primary marine aerosol?, J. Geophys. Res.-Atmos., 118, 4964-4973, doi:10.1002/jgrd.50417, 2013.

Rosilio, V. and Baszkin, A.: Polysaccharides at Interfaces, in: Physical Chemistry of Biological Interfaces, edited by: Baszkin, A. and Norde, W., 155-169, Marcel Dekker, New York, 2000.

Russell, L. M., Hawkins, L. N., Frossard, A. A., Quinn, P. K., and Bates, T. S.: Carbohydrate-like composition of submicron atmospheric particles and their production from ocean bubble bursting, P. Natl. Acad. Sci. USA, 107, 6652-6657, doi:10.1073/pnas.0908905107, 2010.

Russell, L. M., Sorooshian, A., Seinfeld, J. H., Albrecht, B. A., Nenes, A., Ahlm, L., Chen, Y.-C., Coggon, M., Craven, J. S., Flagan, R. C., Frossard, A. A., Jonsson, H., Jung, E., Lin, J. J., Metcalf, A. R., Modini, R., Mülmenstädt, J., Roberts, G. C., Shin- 
gler, T., Song, S., Wang, Z., and Wonaschütz, A.: Eastern Pacific Emitted Aerosol Cloud Experiment, Bull. Am. Met. Soc., 94, 709-729, 2013.

Sallee, V. L. and Dietschy, J. M.: Determinants of intestinal mucosal uptake of short- and medium-chain fatty acids and alcohols, J. Lipid Res., 14, 475-484, 1973.

Sarmiento, J. L. and Gruber, N.: Ocean biogeochemical dynamics, Princeton University Press, Princeton, 472 pp., 2006.

Schmitt-Kopplin, P., Liger-Belair, G., Koch, B. P., Flerus, R., Kattner, G., Harir, M., Kanawati, B., Lucio, M., Tziotis, D., Hertkorn, N., and Gebefügi, I.: Dissolved organic matter in sea spray: a transfer study from marine surface water to aerosols, Biogeosciences, 9, 1571-1582, doi:10.5194/bg-9-1571-2012, 2012.

Sciare, J., Favez, O., Sarda-Esteve, R., Oikonomou, K., Cachier, H., and Kazan, V.: Long-term observations of carbonaceous aerosols in the Austral Ocean atmosphere: Evidence of a biogenic marine organic source, J. Geophys. Res., 114, D15302, doi:10.1029/2009JD011998, 2009.

Sebba, F. and Briscoe, H. V. A.: The variation of the solubility of unimolecular films with surface pressure, and its effect on the measurement of true surface pressure, J. Chem. Soc., 1940, 114118, doi:10.1039/JR9400000114, 1940.

Sekelsky, A. M. and Shreve, G. S.: Kinetic model of biosurfactantenhanced hexadecane biodegradation by Pseudomonas aeruginosa, Biotechnology and bioengineering, 63, 401-409, 1999.

Shiraiwa, M., Zuend, A., Bertram, A., and Seinfeld, J. H.: Gasparticle partitioning of atmospheric aerosols: Interplay of physical state, non-ideal mixing and morphology, PCCP Phys. Chem. Ch. Ph., 15, 11441-11453, doi:10.1039/C3CP51595H, 2013.

Shogren, R. and Biresaw, G.: Surface properties of water soluble maltodextrin, starch acetates and starch acetates/alkenylsuccinates, Colloids and Surfaces A: Physicochemical and Engineering Aspects, 298, 170-176, 2007.

Skop, R., Viechnicki, J., and Brown, J.: A model for microbubble scavenging of surface-active lipid molecules from seawater, J. Geophys. Res., 99, 16395-16402, 1994.

Spiel, D.: More on the births of jet drops from bubbles bursting on seawater surfaces, J. Geophys. Res.-Oceans, 102, 5815-5821, 1997.

Spiel, D. E.: The number and size of jet drops produced by air bubbles bursting on a fresh water surface, J. Geophys. Res.-Oceans, 99, 10289-10296, doi:10.1029/94JC00382, 1994.

Spiel, D. E.: On the births of film drops from bubbles bursting on seawater surfaces, J. Geophys. Res.-Oceans, 103, 24907-24918, doi:10.1029/94JC03055, 1998.

Stephen, A. (Ed.): Food polysaccharides and their application, Marcel Dekker, Inc., New York, 672 pp., 1995.

Sutherland, K.: Physical chemistry of flotation. XI. Kinetics of the flotation process, J. Phys. Chem.-US, 52, 394-425, 1948.

Svenningsson, B., Rissler, J., Swietlicki, E., Mircea, M., Bilde, M., Facchini, M. C., Decesari, S., Fuzzi, S., Zhou, J., Mønster, J., and Rosenørn, T.: Hygroscopic growth and critical supersaturations for mixed aerosol particles of inorganic and organic compounds of atmospheric relevance, Atmos. Chem. Phys., 6, 1937-1952, doi:10.5194/acp-6-1937-2006, 2006.

Tajima, K., Muramatsu, M., and Sasaki, T.: Radiotracer studies on adsorption of surface active substance at aqueous surface. I. Ac- curate measurement of adsorption of tritiated sodium dodecylsulfate, B. Chem. Soc. Jpn., 43, 1991-1998, 1970.

Takahama, S., Liu, S., and Russell, L.: Coatings and clusters of carboxylic acids in carbon-containing atmospheric particles from spectromicroscopy and their implications for cloudnucleating and optical properties, J. Geophys. Res., 115, D01202, doi:10.1029/2009JD012622, 2010.

Tanoue, E.: Occurrence and characterization of particulate proteins in the Pacific Ocean, Deep Sea Research Part A, Oceanographic Research Papers, 39, 743-761, 1992.

Ter Minassian-Saraga, L.: Recent work on spread monolayers, adsorption and desorption, J. Colloid Interf. Sci., 11, 398-418, 1956.

Tranvik, L. and Kokalj, S.: Decreased biodegradability of algal DOC due to interactive effects of UV radiation and humic matter, Aquat. Microb. Ecol., 14, 301-307, 1998.

Tsai, W.-T. and Liu, K.-K.: An assessment of the effect of sea surface surfactant on global atmosphere-ocean $\mathrm{CO} 2$ flux, J. Geophys. Res., 108, 3127, doi:10.1029/2000JC000740, 2003.

Tseng, R., Viechnicki, J., Skop, R., and Brown, J.: Sea-to-air transfer of surface-active organic compounds by bursting bubbles, J. Geophys. Res., 97, 5201-5206, 1992.

Tuckermann, R.: Surface tension of aqueous solutions of watersoluble organic and inorganic compounds, Atmos. Environ., 41, 6265-6275, 2007.

Tuckermann, R. and Cammenga, H. K.: The surface tension of aqueous solutions of some atmospheric water-soluble organic compounds, Atmos. Environ., 38, 6135-6138, 2004.

Turpin, B. J. and Lim, H.-J.: Species contributions to PM2. 5 mass concentrations: Revisiting common assumptions for estimating organic mass, Aerosol Sci. Tech., 35, 602-610, 2001.

Van Vleet, E. S. and Williams, P. M.: Surface potential and film pressure measurements in seawater systems, Limnol. Oceanogr., 28, 401-414, 1983.

Verity, P. G., Williams, S. C., and Hong, Y.: Formation, degradation, and mass: volume ratios of detritus derived from decaying phytoplankton, Mar. Ecol.-Prog. Ser., 207, 53-68, 2000.

Vignati, E., Facchini, M. C., Rinaldi, M., Scannell, C., Ceburnis, D., Sciare, J., Kanakidou, M., Myriokefalitakis, S., Dentener, F., and O'Dowd, C. D.: Global scale emission and distribution of seaspray aerosol: sea-salt and organic enrichment, Atmos. Environ., 44, 670-677, doi:10.1016/j.atmosenv.2009.11.013, 2010.

Vojvodić, V. and Ćosović, B.: Fractionation of surface active substances on the XAD-8 resin: Adriatic Sea samples and phytoplankton culture media, Mar. Chem., 54, 119-133, 1996.

Vorum, H., Brodersen, R., Kragh-Hansen, U., and Pedersen, A. O.: Solubility of long-chain fatty acids in phosphate buffer at $\mathrm{pH}$ 7.4, Biochimica et Biophysica Acta (BBA)-Lipids and Lipid Metabolism, 1126, 135-142, 1992.

Wakeham, S. G., Lee, C., Hedges, J. I., Hernes, P. J., and Peterson, M. J.: Molecular indicators of diagenetic status in marine organic matter, Geochim. Cosmochim. Ac., 61, 5363-5369, 1997.

Wanninkhof, R., Asher, W. E., Ho, D. T., Sweeney, C., and McGillis, W. R.: Advances in quantifying air-sea gas exchange and environmental forcing, Annu. Rev. Marine Sci., 1, 213-244, doi:10.1146/annurev.marine.010908.163742, 2009.

Weber, M. E., Blanchard, D. C., and Syzdek, L. D.: The mechanism of scavenging of waterborne bacteria by a rising bubble, Limnol. Oceanogr., 28, 101-105, 1983. 
Weisiger, R. A. and Zucker, S. D.: Transfer of fatty acids between intracellular membranes: roles of soluble binding proteins, distance, and time, Am. J. Physiol.-Gastr. L., 282, G105-G115, 2002.

Westervelt, D. M., Moore, R. H., Nenes, A., and Adams, P. J.: Effect of primary organic sea spray emissions on cloud condensation nuclei concentrations, Atmos. Chem. Phys., 12, 89-101, doi:10.5194/acp-12-89-2012, 2012.

Wilke, C. R. and Chang, P.: Correlation of diffusion coefficients in dilute solutions, A. I. Ch. E. Journal, 1, 264-270, 1955.
Wurl, O. and Holmes, M.: The gelatinous nature of the sea-surface microlayer, Mar. Chem., 110, 89-97, 2008.

Wurl, O., Wurl, E., Miller, L., Johnson, K., and Vagle, S.: Formation and global distribution of sea-surface microlayers, Biogeosciences, 8, 121-135, doi:10.5194/bg-8-121-2011, 2011.

Ẑutić, V., Ćosović, B., Marčenko, E., Bihari, N., and Kršinić, F. Surfactant production by marine phytoplankton, Mar. Chem., 10, 505-520, 1981. 